\title{
Development of a parallel sampling and analysis method for the elucidation of gas/particle partitioning of oxygenated semi-volatile organics: a limonene ozonolysis study
}

\author{
S. Rossignol ${ }^{1,2}$, L. Chiappini ${ }^{1}$, E. Perraudin ${ }^{2, *}$, C. Rio $^{1}$, S. Fable ${ }^{1}$, R. Valorso ${ }^{2}$, and J. F. Doussin ${ }^{2}$ \\ ${ }^{1}$ Institut National de l'Environnement Industriel et des Risques, Parc Technologique ALATA, \\ 60550 Verneuil-en-Halatte, France \\ ${ }^{2}$ LISA, Universités Paris-Est-Créteil et Paris Diderot, CNRS UMR7583, 61 Av. du Général de Gaulle, 94010 Créteil, France \\ *now at: EPOC, University of Bordeaux, CNRS UMR5805, 351 Cours de la Libération, 33400 Talence, France
}

Correspondence to: L. Chiappini (laura.chiappini@ineris.fr)

Received: 9 January 2012 - Published in Atmos. Meas. Tech. Discuss.: 6 February 2012

Revised: 3 May 2012 - Accepted: 25 May 2012 - Published: 27 June 2012

\begin{abstract}
The gas/particle partitioning behaviour of the semi-volatile fraction of secondary organic matter and the associated multiphase chemistry are key features to accurately evaluate climate and health impacts of secondary organic aerosol (SOA). However, today, the partitioning of oxygenated secondary species is rarely assessed in experimental SOA studies and SOA modelling is still largely based on estimated partitioning data. This paper describes a new analytical approach, solvent-free and easy to use, to explore the chemical composition of the secondary organic matter at a molecular scale in both gas and particulate phases. The method is based on thermal desorption (TD) of gas and particulate samples, coupled with gas chromatography (GC) and mass spectrometry (MS), with derivatisation on sampling supports. Gaseous compounds were trapped on Tenax TA adsorbent tubes pre-coated with pentafluorobenzylhydroxylamine (PFBHA) or N-Methyl-N( $t$-butyldimethylsilyl)trifluoroacetamide (MTBSTFA). Particulate samples were collected onto quartz or Teflon-quartz filters and subsequently subjected to derivatisation with PFBHA or MTBSTFA before TD-GC/MS analysis. Method development and validation are presented for an atmospherically relevant range of organic acids and carbonyl and hydroxyl compounds. Application of the method to a limonene ozonolysis experiment conducted in the EUPHORE simulation chamber under simulated atmospheric conditions of low concentrations of limonene precursor and relative humidity, provides an overview of the method capabilities. Twenty-
\end{abstract}

five compounds were positively or tentatively identified, nine being in both gaseous and particulate phases; and twelve, among them tricarboxylic acids, hydroxyl dicarboxylic acids and oxodicarboxylic acids, being detected for the first time.

\section{Introduction}

Atmospheric formation of particulate matter from the gasto-particle transfer of organics during their atmospheric oxidation is now considered as one of the main phenomena involved in both air quality and climate issues (IPCC, 2007; Hallquist et al., 2009). A better understanding of the interrelated processes and an improved representation in models are still required (Kanakidou et al., 2005). Secondary organic aerosol (SOA) formation is commonly described by gas-to-particle conversion of semi- and non-volatile secondary species formed in the gas phase by atmospheric oxidation of volatile organic compound (VOC) precursors (e.g. Odum et al., 1996; Seinfeld and Pankow, 2003; Asher and Pankow, 2006). However, for SOA formation and evolution pathways, in addition to the initial gas-phase oxidation processes, a significant number of studies in the last decade have pointed out the role of multiphase chemical processes in the particle phase (e.g. Graber and Rudich, 2006; Kroll et al., 2007; Healy et al., 2008; Monks et al., 2009) or at the gas-particle interface (e.g. Rudich, 2003; Rudich et al., 2007). These processes involve continuous modification

Published by Copernicus Publications on behalf of the European Geosciences Union. 
of the chemical composition of SOA and its physicochemical properties and interdependently influence the partitioning of semi-volatile organic species (SVOCs) between gaseous and aerosol phases, thereby consuming or forming SVOCs (Healy et al., 2008).

Hence, understanding multiphase chemical processes is today a key issue to assess both aerosol climate impacts and health effects. It can improve climate impact evaluation through modelling enhancement of formation and evolution pathways and characterisation of aerosol physical properties. In terms of health issues, knowledge of SOA formation pathways and fine particle composition in different outdoor/indoor conditions is required for toxicological evaluation.

In spite of large progress made in recent years (e.g. Donahue et al., 2006; Camredon et al., 2010; Parikh et al., 2011), current SOA formation and evolution modelling often suffer from discrepancies between modelling results and observations (e.g. Volkamer et al., 2007; Chan et al., 2009; Pankow, 2011), notably revealing gaps in our knowledge of SOA formation and aging pathways. Atmospheric chemistry models integrating SOA formation are usually based on the parameterisation of $\mathrm{SVOC}_{i}$ gas-particle partitioning proposed by Pankow (1994). This parameterisation is based on the definition of an equilibrium partitioning coefficient $K_{\mathrm{p}, i}$ $\left(\mathrm{m}^{3} \mu \mathrm{g}^{-1}\right)$ :

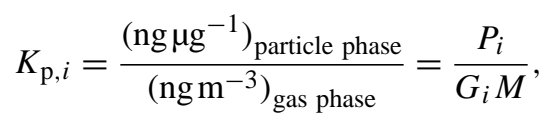

where $P_{i}$ is the mass concentration $\left(\mathrm{ng} \mathrm{m}^{-3}\right.$ air) of the $\mathrm{SVOC}_{i}$ in the particle phase, $G_{i}$ is the mass concentration (ng m${ }^{-3}$ air) of the $\mathrm{SVOC}_{i}$ in the gas phase and $M$ is the mass concentration $\left(\mu \mathrm{g} \mathrm{m}^{-3}\right.$ air) of the total sorbing particle phase. While Eq. (1) is independent of the nature of the sorption process - i.e. adsorption or absorption (Lazaridis, 1999) - most of the models assume an absorptive gas/liquid partitioning of SVOCs. This mechanism is expected to be predominant in SOA formation (Pankow, 1994; Odum et al., 1996) and links $K_{\mathrm{p}, i}$ with the saturation vapour pressure of the $\mathrm{SVOC}_{i}$ through the Eq. (2):

$K_{\mathrm{p}, i}=\frac{760 R T}{10^{6} \overline{\mathrm{MW}_{\mathrm{om}}} \gamma_{i} P_{\mathrm{L}, i}^{\mathrm{o}}}$,

where $R\left(\mathrm{~m}^{3}\right.$ atm mol$\left.{ }^{-1} \mathrm{~K}^{-1}\right)$ is the ideal gas constant, $T(\mathrm{~K})$ is temperature, $\overline{\mathrm{MW}_{\mathrm{om}}}\left(\mathrm{g} \mathrm{mol}^{-1}\right)$ is the average molecular weight of the absorbing particulate material, $\gamma_{i}$ is the activity coefficient of compound $i$ in the particulate phase, and $P_{\mathrm{L}, i}^{\mathrm{o}}$ (Torr) is the vapour pressure of compound $i$ as a pure liquid (subcooled, if necessary).

SOA modelling based on chemical oxidation schemes (e.g. Jenkin, 2004; Camredon et al., 2007; Bessagnet et al., 2008; Chan et al., 2009; Valorso et al., 2011) generally estimate the theoretical $P_{\mathrm{L}, i}^{\mathrm{o}}$ using group contribution methods (e.g. Arp and Goss, 2009; Barley and McFiggans, 2010) and usually sets $\gamma_{i}$ to unity, owing to experimental determination difficulties. This can lead to uncertainties that are suspected to account for observed discrepancies between models and ambient observations in SOA yields. Another likely major source of discrepancies could be the poor consideration of multiphase chemical processes as a sink or source of SVOCs (Chan et al., 2009). An alternative modelling approach to the mechanistic description of SOA is the volatility basis set (VBS) (Donahue et al., 2006, 2009; Cappa and Jimenez, 2010; Farina et al., 2010; Tsimpidi et al., 2010) which is based on distribution of the considered organic matter mass into volatility classes according to their saturation mass concentration $C_{i}^{*}$ (corresponding to the inverse of the Pankow type partitioning coefficient). In this case, the dilution process and the evolution of particulate mass are the driving features. While the VBS scheme does not directly integrate chemical mechanisms, it takes reactivity into account by considering a redistribution of the organic mass from one volatility bin to another. VBS consequently requires data to link atmospherically relevant partitioning behaviour to the origin of the organic aerosol and its composition. This context highlights the requirement for improving our comprehension of multiphase chemical mechanisms, especially those driving the formation of SVOCs and their consumption, and providing atmospherically relevant data on the partitioning behaviour of SVOCs. There is therefore a strong need to simultaneously explore the molecular composition of both gas and particulate phases in SOA studies, and to systematically determine the observed partitioning of SVOCs. The related experimental data have to be evaluated not only with low-concentration simulation chamber experiments but also using ambient atmospheres to assess the relevance of the obtained results.

However, since atmospheric secondary organic matter results from complex and successive oxidation processes, it is highly functionalised and reactive. It contains oxygenated moieties such as aldehyde, keto, hydroxyl, and carboxylic acid groups. Exploring SOA chemical composition and the associated gas phase at a molecular scale is consequently a true analytical challenge (Prather et al., 2008). This is emphasised when the atmospherically relevant constraints of low concentration levels and relative humidity are taken into account.

Until today, only a few studies have assessed the partitioning of secondary organic compounds through determination of partitioning coefficients $K_{\mathrm{p}}$ for individual secondary species. Some papers report the use of a thermodenuder (de Gouw and Warneke, 2007; Grieshop et al., 2009; Lee et al., 2011) in order to evaluate the volatility of SOA formed from different precursors without information on the chemical composition. In these studies, SOA formed in simulated atmospheres flows through and evaporates in a temperaturecontrolled tube, previously calibrated with compounds with a known vapour pressure. By this method SOA mass is divided 
into volatility classes with known vapour pressure ranges, providing a volatility distribution. This method is very useful to provide atmospheric relevant constraints for modelling based on the Volatility Basis Set (Grieshop et al., 2009) and evaluate the semi-volatile and non-volatile fractions of SOA. Nevertheless, it remains incomplete as it provides no insights into chemical processes.

Studies aiming at elucidating chemical processes focus on the characterisation of the chemical composition of secondary organic matter at a molecular scale. However, while the aerosol phase is most often analysed by chromatographic off-line methods to explore its highly complex molecular composition, the gas-phase products are most often monitored by an on-line method providing limited insights into the molecular composition. Today, proton transfer reaction mass spectrometry (PTR-MS) is the most widely employed on-line technique for assessing the chemical composition of the gas phase (e.g. Blake et al., 2004; Kroll et al., 2006), as it provides continuous molecular information and quantification of gas-phase compounds at very low concentration levels (around $10 \mathrm{ppt}$ ) without interference of water, making it usable in the ambient atmosphere. Nevertheless, PTR-MS is not specific as it does not provide detailed structural information.

Chromatographic methods using an on- or off-line approach, often coupled with thermal desorption, are sometimes applied to elucidate the molecular composition of the gas phase. However, apart from a few approaches using derivatisation strategies (e.g. Ho and Yu, 2002, 2004; Temime et al., 2007; Pacolay et al., 2008), these techniques are restricted to non-polar or mono-functionalised compounds (e.g. Wedel et al., 1998; Xu et al., 2003; Sinha et al., 2010) with limited applications to secondary chemistry studies.

Studies aiming at elucidating the underlying mechanisms of SOA formation focus on the chemical composition of the particulate phase. For this purpose, a wider range of powerful analytical methods exists, mainly because of the chemical complexity of the aerosol and its diversity, which can be divided into on-line and off-line methods (Hallquist et al., 2009). Over the past decade, on-line real-time aerosol mass spectrometry (AMS) has become a technique of choice to explore the chemical composition of the aerosol phase with a high time resolution (Sullivan and Prather, 2005; Canagaratna et al., 2007). Combining direct thermal extraction of sampled airborne aerosol (flash vaporisation upon impaction on a hot surface, $\sim 600^{\circ} \mathrm{C}$, under high vacuum) with electron ionisation (EI) and mass spectrometry, the AMS technique provides data on the bulk chemical nature of particulate organic matter - sulphate, nitrate, ammonium and chloride contents, and the oxidation state with function type identification (alcohols, carboxylic acids and carbonyls) - and is consequently a powerful tool for the chemical and physical characterisation of SOA. It has been successfully applied to both ambient (e.g. Zhang et al., 2011) and simulated atmospheres (e.g. Sato et al., 2010). However, complex EI mass spectra resulting from extensive fragmentation do not allow for the unambiguous identification of individual organic compounds, which limits the exploration of the composition at a molecular scale.

Another interesting in-situ method is thermal desorption aerosol gas chromatography (TAG instrument), based on coupling thermal desorption of the aerosol with gas chromatography/mass spectrometry (GC/MS) or GC-flame ionisation detection (GC-FID) (Williams et al., 2006). Recently improved by GC $\times$ GC separation (2D-TAG, Goldstein et al., 2008; Isaacman et al., 2011), TAG provides detailed data on the volatility distribution of the particle components with a good time resolution (from 1 to $2 \mathrm{~h}$ ). However, GC separation limits TAG detection and the identification range to nonpolar and mono-functionalised compounds, so that it does not allow to obtain insights into SOA chemistry.

Off-line chromatographic methods are required to address the high complexity of SOA composition. The methods differ in a first instance by the extraction step. Hays and Lavrich (2007) provided an interesting review on thermal desorption-gas chromatography/mass spectrometry (TD/GC/MS) applied to fine aerosol. TD is a very convenient extraction method as it can be fully automated and is inexpensive, sensitive and solvent-free. However, like on-line TAG, this technique is limited by the polarity of SOA components. To overcome this limitation, an in-situ derivatisation step can be introduced. A few recent studies have integrated this principle, exposing sample filters to a derivatisation reagent for methylation or trimethylsilylation during thermal desorption for the detection and quantification of mono- and dicarboxylic acids (Beiner et al., 2009; Sheesley et al., 2010; Orasche et al., 2011). Other extraction techniques, more scarcely used, have also been reported. As an example, supercritical fluid extraction (SFE) couples the extraction step directly to the analytical process. Its efficiency for extracting organic compounds from complex matrices has been demonstrated by coupling SFE with GC/MS or liquid chromatography/GC/MS (LC/GC/MS) (Hansen et al., 1995; Forstner et al., 1997; Castells et al., 2003). The process has the advantage in that it allows derivatisation of polar compounds during the static extraction step (Shimmo et al., 2004; Chiappini et al., 2006). Nevertheless, the large majority of studies exploring the chemical composition of fine organic aerosol is based on a first solvent sample extraction step as it provides several possibilities for further analytical processes. Solvent extraction type and steps to be considered (solvents choice, ultrasonication, Soxhlet, preconcentrations steps, derivatisation, etc.) are selected according to both the fraction of the organic mass studied (water-soluble organic compounds, polycyclic aromatic hydrocarbons, carbonyl, carboxyl and/or hydroxyl compounds, organosulphates, organonitrates, oligomers, humic-like substances, etc.) and the analytical technique employed (GC, LC, ion chromatography - IC, electrophoresis, etc.). Mass 
spectrometric analysis is widely used for identification and quantification. Among the various possible combinations, those aiming at analysis of polar and functionalised compounds (compounds containing, for example, carbonyl, carboxyl and/or hydroxyl groups) are mainly divided between GC/MS analysis with prior derivatisation (e.g. Nolte et al., 2001; Claeys et al., 2004, 2007; Edney et al., 2005; Szmigielski et al., 2007; Chan et al., 2010; Vivanco et al., 2011) and LC/soft ionisation-MS analysis [electrospray ionisation (ESI-MS) or atmospheric pressure chemical ionisation (APCI-MS)] (e.g. Wan and Yu, 2007; Gómez-González et al., 2008; Kitanovski et al., 2011). These techniques are constantly being improved and made more complex in order to improve detection limits, enlarge the range of separable species $(\mathrm{GC} \times \mathrm{GC}, \mathrm{LC} \times \mathrm{LC})$, or increase the structural characterisation capability through higher-order $\mathrm{MS}\left(\mathrm{MS}^{n}\right)$ or high-resolution MS (e.g. ion trap - ITMS, Time of Flight ToFMS, Fourier Transform Ion Cyclotron Resonance Mass Spectrometry - FTICR-MS) (e.g. Hamilton et al., 2005; Pol et al., 2006; Claeys et al., 2009; Yasmeen et al., 2011; Hamilton et al., 2011). Nevertheless, while solvent extraction has proven useful for subsequent quantification and precise molecular structure identification, related protocols are time-consuming, and are prone to contamination and losses, especially for the semi-volatile fraction, during the different extraction steps.

Global approaches considering gas and particulate phases simultaneously are required to elucidate secondary organic matter at a molecular scale for both phases and to provide relevant partitioning data for SVOCs. Most works aiming at studying the partitioning of SVOCs are based on off-line chromatographic techniques coupled to mass spectrometry, for both phases. This approach involves simultaneous sampling of both gas and particulate phases. One of the most common sampling methods is to trap gas-phase compounds on one or more annular glass denuders (XAD4 coated) placed in series with a filter collecting the aerosol phase. This sampling technique has been applied without any derivatisation step prior to gas GC/MS analysis to investigate gas/particle partitioning of non-polar compounds - alkanes, PAHs (Volckens and Leith, 2003), or small carbonyls in diesel exhaust (Lee et al., 2004; Jakober et al., 2008). In more specific SOA studies targeting poly-functionalised and reactive compounds (carbonyls, hydroxyls and carboxyls), a derivatisation step has been introduced prior to the chromatographic separation. After solvent extraction of both denuder and filter, each sample is derivatised, in the liquid phase, by oximation with pentafluorobenzylhydroxylamine (PFBHA). Extracts are reduced in volume and blown to dryness before reconstitution in a suitable solvent. Double derivatisation is then performed by additional trimethylsilylation with N,O-bis(trimethylsilyl)trifluoroacetamide (BSTFA). Subsequently, aliquots of the doubly-derivatised extracts are injected into the GC/MS instrument (e.g. Woo and Kim, 1999; Kalberer et al., 2000; Jaoui et al., 2003). Alternative derivati- sation reagents have occasionally been employed, such as the $\mathrm{BF}_{3}$-methanol reagent (Jaoui and Kamens, 2003). In spite of its powerful capacity to identify and quantify individual species in complex mixtures of poly-functionalised compounds, this procedure presents the disadvantage of solvent extraction. More recently, the same simultaneous sampling technique of both gas and particulate phases onto a denuder/filter pack has been improved for carbonyl measurements, where PFBHA is used prior to sampling to coat the XAD-4 denuder and impregnate the filter(s) (Temime et al., 2007; Healy et al., 2008, 2009; Ortiz et al., 2009). The sample treatment is thus reduced to a simple extraction of the sampling supports, denuders and filters, possibly followed by a solvent reduction step and/or a filtering step. However, this method is reserved to carbonyls and solvent extraction is still required.

In this study, we present a new analytical approach to explore, simultaneously and in parallel, the chemical composition of both gas and particulate phases, and to quantify the partitioning of individual and poly-functionalised SVOCs. Reducing both solvent use and time-consuming sample treatment steps, the new method is based on thermal desorption of both gas and particulate phases sampling supports, coupled to GC/MS. It involves on-sorbent derivatisation of gas-phase compounds and on-filter derivatisation of particulate-phase compounds.

The validation of the method is presented as well as its application to smog chamber experiments. As to the latter experiments, two series of simulated atmosphere experiments were performed in the EUPHORE European reactor. A first series focuses on limonene ozonolysis chemical system, whereas a second one focuses on the isoprene photooxidation chemical system. Results from these experiments are used here to illustrate the capability of the method to explore the chemical composition of the secondary organic matter in both gas and particulate phases.

\section{Materials}

\subsection{Chemical}

\subsubsection{Standards}

The standards used for the method development were chosen in order to fulfil the following purposes: (i) represent a wide range of functionalised semi-volatile secondary organic compounds; and (ii) facilitate the identification and quantification of secondary products that are expected from limonene ozonolysis (as this system has been chosen as a model system). Each series of compounds used for the different method characterisation tests is chosen in order to meet both experimental requirements and objectives. All chemicals were purchased from Sigma-Aldrich Co. (St. Louis, USA) with the exception of 4-oxopentanal, available from Diverchim SA 


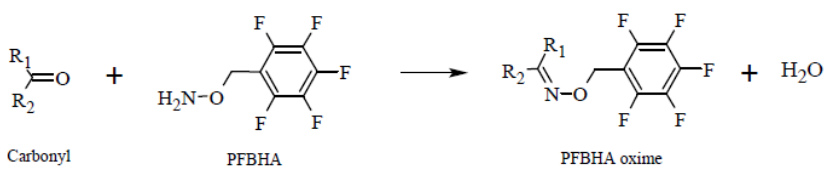

Fig. 1. Derivatisation reaction of carbonyl compounds by the PFBHA reagent.

(Montataire, France). Given the large number of compounds used for both analytical development and application of the method to limonene ozonolysis, a complete list is provided in the Supplement.

\subsubsection{Derivatisation reagents}

Derivatisation of oxygenated species blocks the reactive functions, reduces their polarity and consequently enhances GC/MS response factors. Two derivatisation reagents were employed in order to derivatise either carbonyl compounds or carboxyl and hydroxyl compounds. $O$ - $(2,3,4,5$, 6pentafluorobenzyl)hydroxylamine (PFBHA, purchased from Sigma-Aldrich: PFBHA hydrochloride, puriss. p.a., derivatisation grade for $\mathrm{GC}, \geq 99.0 \%$ ) was used to derivatise carbonyl compounds (aldehydes and ketones). The PFBHA derivatisation reaction (Fig. 1) forms oximes that provide characteristic fragmentation in MS and enhance detection limits. It is the most frequently used reagent in SOA studies to derivatise carbonyl groups for GC/MS analysis (e.g. Wu and Hee, 1995; Jaoui et al., 2006; Carrasco et al., 2007; Healy et al., 2008; Ortiz et al., 2009). The reaction is commonly performed in aqueous or water-containing solution (Cancilla and Que Hee, 1992). N-Methyl-N-( $t$-butyldimethylsilyl)trifluoroacetamide (MTBSTFA, purchased from Regis ${ }^{\circledR}$ Technologies Inc., MTBSTFA $+1 \% t$-BDMCS) was used to derivatise carboxyl and hydroxyl compounds. MTBSTFA converts hydroxyl and carboxyl groups (Fig. 2) to form $t$-butyldimethylsilyl (TBDMS) esters with increased volatility compared to the parent compounds, and consequently extends the range of semi- and non-volatile compounds observable in GC analysis. BSTFA is more widely employed in SOA studies for derivatisation of hydroxyl and carboxyl groups than MTBSTFA (e.g. Kleindienst et al., 2004; Jaoui et al., 2006; Pietrogrande and Bacco, 2011); nevertheless, MTBSTFA was chosen since $t$ butyldimethylsilyl derivatives formed with MTBSTFA provide similar fragmentation pathways as trimethylsilyl derivatives formed with BSTFA but are less sensitive to hydrolysis.

\subsubsection{Adsorbent}

Gas-phase sampling is achieved on adsorbent support. Tenax ${ }^{\circledR}$ TA was chosen based on three criteria: (1) its chemical inertness, (2) its capacity to trap compounds with a large range of volatility, and (3) its highly hydrophobic nature. Commercial Tenax ${ }^{\circledR}$ TA sorbent tubes were purchased

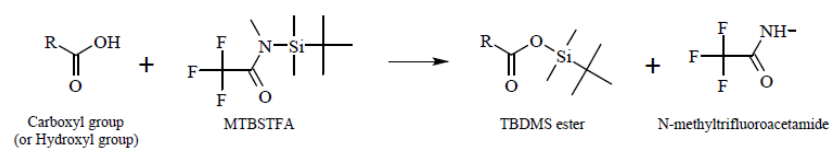

Fig. 2. Derivatisation reaction of carboxyl or hydroxyl compounds by the MTBSTFA reagent.

from PerkinElmer, Inc. (Waltham, USA, stainless steel ATD Prepacked Sample Tubes, Sorbent: Tenax TA mesh 60/80). Before first use and after use, adsorbent tubes were conditioned overnight under a heated helium flow $\left(295^{\circ} \mathrm{C}\right)$. Adsorbent purity is checked before use by TD-GC/MS analysis.

\subsubsection{Filters}

Particulate phase sampling was achieved on two types of filters in order to meet the different requirements of the two derivatisations performed, with PFBHA and MTBSTFA. To trap, derivatise with PFBHA and analyse the carbonylcontaining fraction of the aerosol phase, high-purity quartz microfibre filters (QM-A grade, $47 \mathrm{~mm}$, Whatman, Whatman International Ltd. Maidstone, UK) were used, as quartz filters are hydrophilic and are the most thermal-resisting filter type commercially available. To trap, derivatise with MTBSTFA and analyse the hydroxyl- and carboxyl-containing fraction of the aerosol phase, pure borosilicate glass fibres filters with fluorocarbon (tetrafluoroethylene, TFE) coating (Fiberfilm $^{\mathrm{TM}}$, $47 \mathrm{~mm}$, PallFlex ${ }^{\circledR}$, Pall Life Sciences, Port Washington, USA) were used, as TFE coating reduces moisture loading during sampling and reactivity of the filter surface and as these filters can be used up to a temperature of $315^{\circ} \mathrm{C}$. Thereafter, Fiberfilm ${ }^{\mathrm{TM}}$ filters are referred to as Teflon-quartz filters. Before use, quartz fibre filters were conditioned by heating at $450{ }^{\circ} \mathrm{C}$ for $5 \mathrm{~h}$ and Teflon-quartz filters by heating at $300^{\circ} \mathrm{C}$ for $5 \mathrm{~h}$.

To trap particles upstream the Tenax TA sorbent tubes, a Teflon filter (Zefluor PTFE membrane filters, Pall Life Sciences, not analysed) was used.

\subsection{Analytical systems}

Two analytical systems were used to perform analytical development owing to the large number of samples to be treated. The TD-GC/MS system was used for constructing calibration curves, evaluating detection limits and analysing simulation chamber samples, while the TD-GC-FID system was preferred above the other system for the analytical development (method optimisation and characterisation tests), as FID response stability over time does not require system recalibration and facilitates comparison of the results. Both systems were used with the same analytical conditions. It goes without saying that only the TD-GC/MS system was used to apply the developed method. 


\subsubsection{Thermal desorption - gas chromatography/mass spectrometry system and procedures}

The thermal desorption (TD) system was composed of (1) an Ultra 50:50 (Markes International, Llantrisant, UK) multitubes auto-sampler equipped with an injected sample split flow automated re-collection system, (2) a Unity 1 (Markes International) platform desorber for single tubes, and (3) an Air Server (Markes International) used in the mass flow controller mode. Samples were desorbed at $300^{\circ} \mathrm{C}$ for $15 \mathrm{~min}$ at a flow rate of $50 \mathrm{ml} \mathrm{min}^{-1}$ and were cryogenically trapped on-Tenax ${ }^{\circledR}$ TA (mesh 60/80) adsorbent at $-10^{\circ} \mathrm{C}$. The trap was desorbed for $\mathrm{GC}$ injection at $300^{\circ} \mathrm{C}$, for $15 \mathrm{~min}$ in order to clean the trap, with a split ratio of 1:9. The "recollection" option of the commercial thermal desorption system was used: the split flow from the injected sample is driven through the original, previously desorbed, Tenax ${ }^{\circledR} \mathrm{TA}$ tube (in the case of a gas-phase sample) or through a freshly cleaned Tenax ${ }^{\circledR}$ TA tube (in the case of the aerosol-phase filter samples), allowing the collection, at ambient temperature, of compounds that otherwise would be lost through the vent exit to be subsequently analysed. The gas chromatography system was a 6890A type instrument from Agilent Technologies equipped with an $\mathrm{Rxi}^{\circledR}{ }^{\circledR}-5 \mathrm{Sil}$ MS column $(60 \mathrm{~m}, 0.25 \mathrm{~mm}$ i.d., film thickness: $0.1 \mu \mathrm{m}$, Restek Corporation, Bellefonte, USA). Samples were chromatographically separated with the following temperature program: from 40 to $305^{\circ} \mathrm{C}$ with a thermal ramp of $10^{\circ} \mathrm{C} \mathrm{min}^{-1}$. The mass spectrometry system was a 5973 type instrument from Agilent Technologies. It was equipped either with an electron ionisation (EI) source (operated at an energy of $70 \mathrm{eV}$ ), used in the case of the first injections of samples for structural identification and quantification, or a chemical ionisation source (CI in positive mode, methane as reagent gas), used in the case of the injection of the re-collected samples to provide complementary structural information.

\subsubsection{Thermal desorption - gas chromatography - flame ionisation detection}

The TD-GC-FID system was composed of a thermal desorber (TurboMatrix 650, Perkin Elmer, Inc.) coupled to a gas chromatograph (Clarus 500, Perkin Elmer, Inc.) and equipped with an $\mathrm{Rxi}^{\circledR}$-5Sil MS column $(60 \mathrm{~m}, 0.25 \mathrm{~mm}$ i.d., film thickness: $0.1 \mu \mathrm{m}$, Restek Corporation, Bellefonte, USA) and a flame ionisation detector. The system was also coupled to a mass spectrometer (Clarus 500, Perkin Elmer, Inc.). The analytical method was the same as that used on the Markes-Agilent TD-GC/MS system. No re-collection was performed for analytical development. The separation of the compounds was achieved with the following temperature program: from 40 to $305^{\circ} \mathrm{C}$ with a thermal ramp of $10^{\circ} \mathrm{C} \mathrm{min}^{-1}$.

\subsection{Simulation chambers}

\subsubsection{INERIS dynamic simulation chamber}

The INERIS dynamic simulation chamber consists of a borosilicate glass loop (2001 volume) which has been described elsewhere (Martin et al., 2003; Gonzalez-Flesca and Frezier, 2005). It has been specifically designed to generate single or multi-component gaseous species atmospheres at known and stable concentrations (from hours to weeks). Clean and dry air was generated by a zero air generator (Claind, AZ Air purifier 2010) and atmospheres were generated by continuous dilution of a concentrated mixture (typically, standard pollutants gas tanks). The dilution process was controlled and monitored by mass flow meters. If required, relative humidity was generated from a pressurised bulb containing ultrapure water $(18.2 \mathrm{M} \Omega$, ElgaPureLab Flex, Veolia water) connected to a heated liquid mass flow controller system. The temperature in the chamber was maintained at around $22^{\circ} \mathrm{C}$ by circulation of a temperatureconditioned mixture of water/ethylene glycol in the chamber double walls. Temperature, pressure and relative humidity were continuously monitored.

\subsubsection{CESAM atmospheric simulation chamber}

The CESAM atmospheric simulation chamber was used to perform determination of breakthrough volumes presented in Sect. 3.2.4. It has been described in detail elsewhere (Wang et al., 2011). Briefly, this facility consists of a cylindrical $4.2 \mathrm{~m}^{3}$ stainless steel chamber. The chamber is evacuable using a powerful pumping system consisting of a root pump, a rotary pump and a turbomolecular pump which allows the evacuation down to $8 \times 10^{-4}$ mbar between each experiment to minimise the memory effects. Both temperature and relative humidity were measured with a HMP234 Vaisala ${ }^{\circledR}$ humidity and temperature transmitter equipped with a capacitive thinfilm polymer sensor Humicap ${ }^{\circledR}$.

Injection of compounds was performed by introducing a precisely known pressure (in the range $0.1 \mathrm{mbar}$ ) via a vacuum ramp from a frozen pure standard solution into a bulb of known volume ( $V=1.08321)$. The bulb content was then immediately flushed into the chamber.

Hydrocarbon products were monitored using a Fourier Transform InfraRed spectrometry (FTIR) instrument from Bruker GmbH. The total optical path length for the in-situ FTIR measurement was set to $192 \mathrm{~m}$.

\subsubsection{EUPHORE simulation chamber}

Simulation chamber experiments on limonene ozonolysis (Sect. 4.) and isoprene photo-oxidation (Sect. 3.3.4) were conducted in chamber B of the EUphore PHOtoREactor (EUPHORE) facility in Valencia (Spain), consisting of $\sim 200 \mathrm{~m}^{3}$ outdoor hemispheric fluorinated ethane/propene (FEP) bags equipped with high power fans. For limonene 


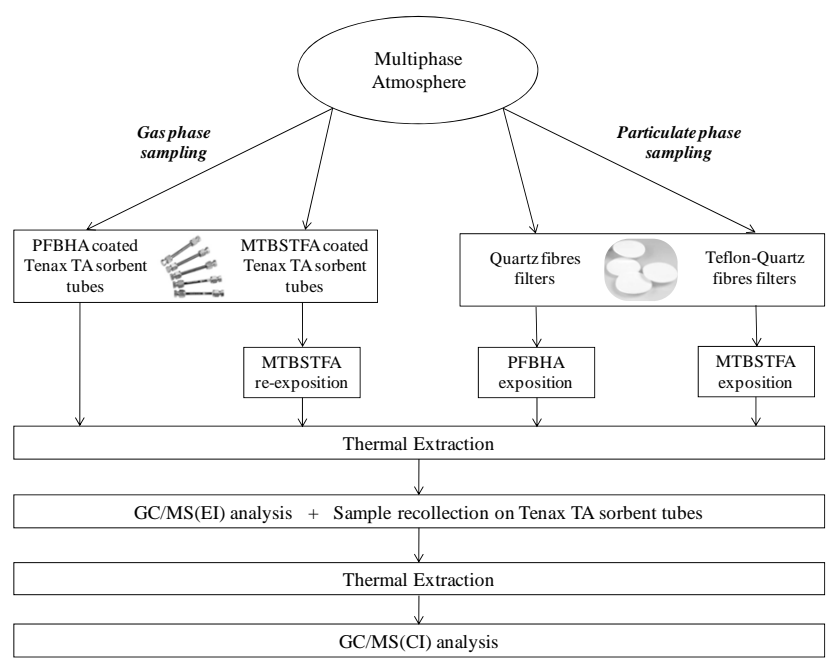

Fig. 3. Method overview.

ozonolysis experiment the chamber was protected from outdoor conditions (irradiation) by a retractable steel cover to achieve dark conditions. Before the experiment, the chamber was flushed overnight and then filled with clean air from an air purification system including an absorption dryer with molecular sieve. Air volume losses due to sampling were compensated by introduction of clean air. Prior to every experiment, an aliquot of $\mathrm{SF}_{6}$ was introduced into the chamber as an inert tracer to determine the dilution rate. Limonene or isoprene was introduced using a heated clean air stream. Relative humidity was generated by water introduction through a sprayer. Humidity and temperature were monitored by a hygrometer model TS-2 (Waltz, Effeltrich, Germany). Pressure was monitored by a barometer model Air DB-VOC (Sirsa, Madrid, Spain). Ozone was produced by passing clean air (Linde, purity of $99,999 \%$ ) through a bulb equipped with a mercury UV lamp. This in-house system was previously calibrated as producing ozone with a typical rate of

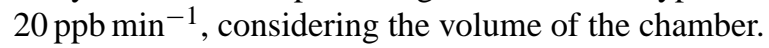

The terpene concentration was monitored by an on-line gas chromatograph coupled with a photoionisation detector (Fisons GC-8160, Thermo-Fisher, Waltham, MA, USA) and equipped with a DB-624 cyano-propylphenylpolysiloxane fused silica capillary column (J\&W Scientific, $30 \mathrm{~m}$, $0.32 \mathrm{~mm}$ id, $1.8 \mu \mathrm{m}$ film), operated isothermally at $160^{\circ} \mathrm{C}$ with a total run time of $10 \mathrm{~min}$. The total aerosol mass was continuously monitored by a tapered element oscillating microbalance (TEOM, model 1400a, Ruppert and Patashnick Co. Inc, Albany, USA) with a one minute averaging time step.

\section{Analytical development}

\subsection{Method overview}

The developed global sampling and analytical method is summarised in Fig. 3. This method is based on the simultaneous sampling of the gaseous phase on Tenax TA sorbent tubes pre-coated with one of the two derivatisation reagents (PFBHA or MTBSTFA), and the particulate phase on filters. Gaseous samples pre-coated with MTBSTFA require re-exposition to the derivatisation reagent after sampling to complete derivatisation. Particulate samples are systematically exposed to one of the two derivatisation reagents after sampling. The method involves TD-GC/MS analysis of all derivatised samples. Both EI and CI modes analyses could be performed for each sample using the sample re-collection option of the commercial thermal desorber.

For each sample type, Tenax-TA tubes and filters, PFBHAand MTBSTFA-derivatised, the thermal desorption efficiency was evaluated for all available standard compounds for the higher mass tested (around $320 \mathrm{ng} \mathrm{sample}^{-1}$ ) by performing a second TD-GC/MS analysis just after the first one. For none of the compounds was a signal observed in the second analysis, suggesting a maximal desorption efficiency under our desorption conditions.

Laboratory blanks were also tested. Only for methylglyoxal and dimethylglyoxal on quartz filters were the observed levels significant and consequently subtracted for constructing calibration curve and estimating detection limits. However, the quartz filter blank reproducibility was not evaluated.

The developed method allows for the use of common VOCs denuders upstream of aerosol collection filters. However, in the present analytical development no denuder was tested.

\subsection{Carbonyl functions derivatisation in gas phase samples}

For the analysis of carbonyl-bearing molecules in the gas phase, the collection of air samples collection was achieved on Tenax ${ }^{\circledR}$ TA sorbent tubes pre-coated with PFBHA. As the derivatisation reaction occurs onto the sorbent of the cartridges, which is not a classical medium for oximation with PFBHA, one of the key parts of this work was the optimisation of this process and its characterisation.

\subsubsection{Sorbent coating and derivatisation}

Tenax ${ }^{\circledR}$ TA coating was achieved in 20 min, without using any solvent by sublimation of PFBHA: a nitrogen stream $\left(100 \mathrm{ml} \mathrm{min}^{-1}\right.$ tube $\left.^{-1}\right)$ was passed through a glass bulb that contained solid PFBHA and was connected to one or more Tenax TA sorbent tubes (max. 8 tubes, Fig. 4). A PFBHA mass of $330 \mu \mathrm{g}(1.3 \mu \mathrm{mol})$ per tube connected was introduced. For a 121 sample volume (corresponding to a sampling flow rate of $100 \mathrm{ml} \mathrm{min}^{-1}$ for $2 \mathrm{~h}$ ), this PFBHA mass 


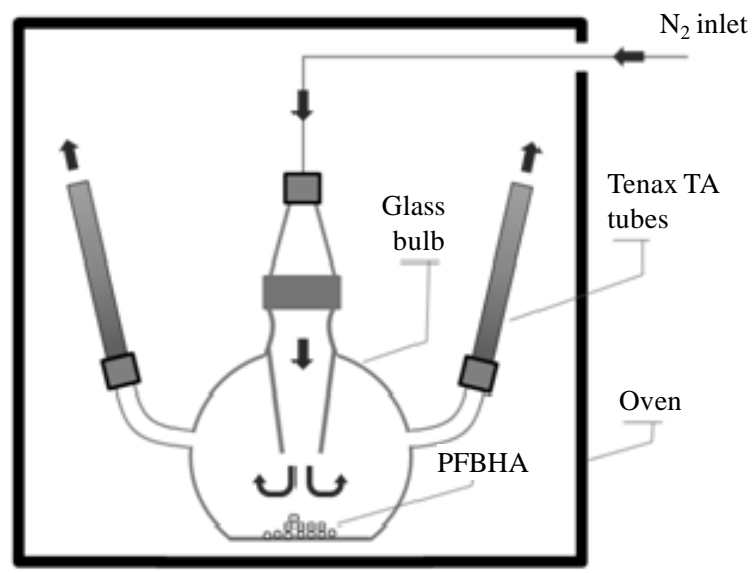

Fig. 4. The PFBHA coating process scheme for Tenax TA tubes.

is sufficient to derivatise (i.e. is 10 times higher than) a carbonyl compound at a concentration of around $1 \mathrm{mg} \mathrm{m}^{-3}$ (for an average molecular weight of 100). The glass bulb and sorbent tubes were kept at $110^{\circ} \mathrm{C}$ in an oven during the coating. Similar to Ho and $\mathrm{Yu}$ (2002), closed samples were stored at room temperature after sampling for a minimum of five days before TD-GC/MS analysis to allow for full derivatisation.

\subsubsection{Humidity influence}

For general purposes, PFBHA derivatisation is usually performed in aqueous or water containing solutions (Cancilla and Que Hee, 1992) and a molecule of water is formed for each derivatised compound (Fig. 1). A positive influence of the humidity present in the sampled air is consequently expected for the derivatisation process. On the other hand, humidity can disturb the collection of compounds by reducing the adsorption efficiency (Harper, 1993; Loedwyckx and Vansant, 2000). In order to evaluate this humidity influence a series of aldehydes was sampled from a dry $(0 \% \mathrm{RH})$ and wet $(50 \% \mathrm{RH})$ simulated atmosphere. The experiment was carried out in the INERIS dynamic simulation chamber. The system was adjusted to generate crotonaldehyde, benzaldehyde, butanal, pentanal and hexanal at concentrations of $11.7,17.7,12.0,14.3$, and $16.7 \mu \mathrm{g} \mathrm{m}^{-3}$, respectively. Sampling was performed during four hours at a sampling flow rate of $150 \mathrm{ml} \mathrm{min}^{-1}$, connecting coated sorbent tubes to the chamber through a sampling cone. Five and six replicates were collected from the $0 \% \mathrm{RH}$ and $50 \% \mathrm{RH}$ atmospheres, respectively. The results are shown in Fig. 5, revealing that humidity in the sampled air promotes trapping and/or derivatisation, 1 with an average response ratio of 2.4 between wet and dry experiments (ranging from 1.9 and 3.6 depending on compounds). A complementary experiment was performed in order to evaluate bias linked with humidity variations within a realistic relative humidity range. Three sampling series of three replicates were collected at 30,50 and $80 \%$ RH. Sampling was performed during one hour at a sam- pling flow rate of $100 \mathrm{ml} \mathrm{min}^{-1}$. The results are shown Fig. 6, revealing no significant bias linked to humidity variations. A relative humidity of $30 \%$ appears to be sufficient to reach a maximum derivatisation yield in these conditions. However, a slight repeatability decrease is observed at $80 \% \mathrm{RH}$, probably due to competition between water and adsorbed organic molecules on adsorbent surface sites. Nevertheless, this observation is consistent with the fact that high humidity levels are known to affect sampling on classic adsorbents, decreasing breakthrough volumes (Harper, 1993; Loedwyckx and Vansant, 2000). The developed method to trap and derivatise gaseous carbonyl compounds can thus be considered as suitable under realistic sampling conditions.

\subsubsection{Derivatisation efficiency and standardisation}

The derivatisation efficiency was tested by comparing insolution derivatisation and on-Tenax ${ }^{\circledR}$ TA derivatisation. Standard solutions were prepared in a 5/95 water/acetonitrile mixture at a concentration of $80 \mathrm{ng}^{-1}$ with 19 carbonyl compounds (eleven aldehydes: methacrolein, pentanal, 2-ethylbutanal, benzaldehyde, nonanal, ethyl-3-methyl-4oxocrotonate, citronellal, citral, glyoxal, perillaldehyde and glutaraldehyde; seven ketones: butanone, 3-buten-2-one, 4heptanone, carvone, 2,3-butadione, 3-methyl-2,4-pentadione and camphor; and one keto-aldehyde: methylglyoxal). For in-solution derivatisation, a molar excess of PFBHA corresponding to ten times the molar concentration of derivatisable functions was added to $1 \mathrm{ml}$ of each solution. The solutions were kept at room temperature (around $22^{\circ} \mathrm{C}$ ) for $24 \mathrm{~h}$. One $\mu \mathrm{l}$ of each of the five derivatised solutions was subsequently vaporised under a heated helium stream $\left(270^{\circ} \mathrm{C}\right)$ and trapped onto five clean Tenax ${ }^{\circledR}$ TA tubes just before TD-GC-FID analysis. The repeatability of the in-solution derivatisation protocol was separately evaluated by estimating the uncertainty of the analytical response of each insolution derivatised compound from a series of four insolution derivatisation replicates. These uncertainties, corresponding to the standard deviation/average value ratio, were found to be satisfactory for all of the compounds, ranging from 0.3 to $29.7 \%$. For on-sorbent derivatisation, one $\mu \mathrm{l}$ of the non-derivatised solutions was injected onto PFBHAcoated Tenax ${ }^{\circledR}$ TA tubes by the same procedure. In order to expose the tubes to humidity, clean and wet $(50 \% \mathrm{RH})$ zero air was sampled onto the tubes during $30 \mathrm{~min}$ at a flow rate of $100 \mathrm{ml} \mathrm{min}^{-1}$. Samples were kept at room temperature for 5 days before TD-GC-FID analysis. Two on-Tenax TA derivatisations per solution were performed. The comparison of the results is shown in Fig. 7. For aldehydes (Fig. 7a), on-Tenax TA derivatisation led to derivatisation efficiency close to or higher than in-solution derivatisation (ratio ranging from 102 to $205 \%$ ), except for methacrolein (9\%). For ketones (Fig. 7b), on-Tenax TA derivatisation led to a derivatisation efficiency lower than for in-solution derivatisation (ratio ranging from 12 to $41 \%$ ) (derivatised 


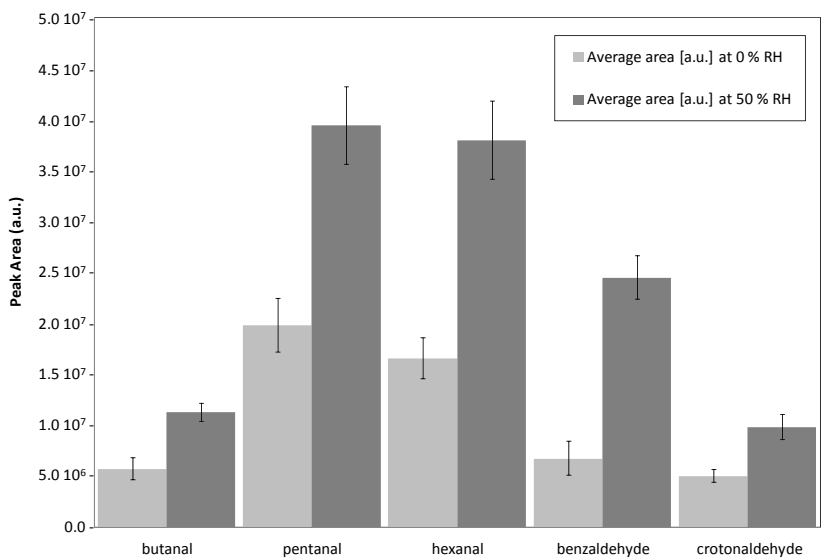

Fig. 5. Gaseous carbonyl compounds sampling on simulated atmosphere in dry $(0 \% \mathrm{RH})$ and wet $(50 \% \mathrm{RH})$ conditions. "Peak Area" refers to the total ion chromatogram obtained in the electron ionisation mode, in area units. Error bars represent \pm one standard deviation determined from six replicates.

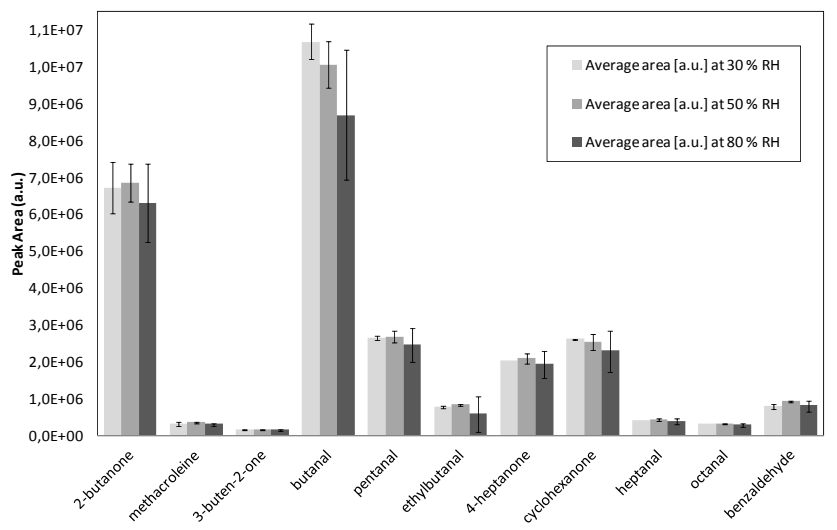

Fig. 6. Gaseous carbonyl compounds sampling on simulated atmosphere in realistic relative humidity range (30, 50 and $80 \% \mathrm{HR})$. "Peak Area" refers to the extracted ion chromatogram obtained in the electron ionisation mode, in area units (ion extraction depends on compound). Error bars represent \pm one standard deviation determined from three replicates.

camphor was not observed in both derivatisation processes). Consequently, even if this test does not allow to determine relevant on-Tenax TA derivatisation yields, it points out the fact that the two procedures (in-solution and on-Tenax TA derivatisations) are not equivalent.

Nevertheless, based on this experiment and previous ones (see Sect. 2.2.2), the repeatability of on-Tenax TA derivatisation was estimated from the standard deviation/mean ratio and determined to be equal to or lower than $10 \%$ for compounds with more than 4 carbons and lower than $20 \%$ for compounds with 4 carbons or less (except for the $80 \% \mathrm{RH}$ experiment). Thus, despite the low derivatisation yield for some compounds, a satisfactory on-Tenax TA derivatisation repeatability was observed, allowing quantification.
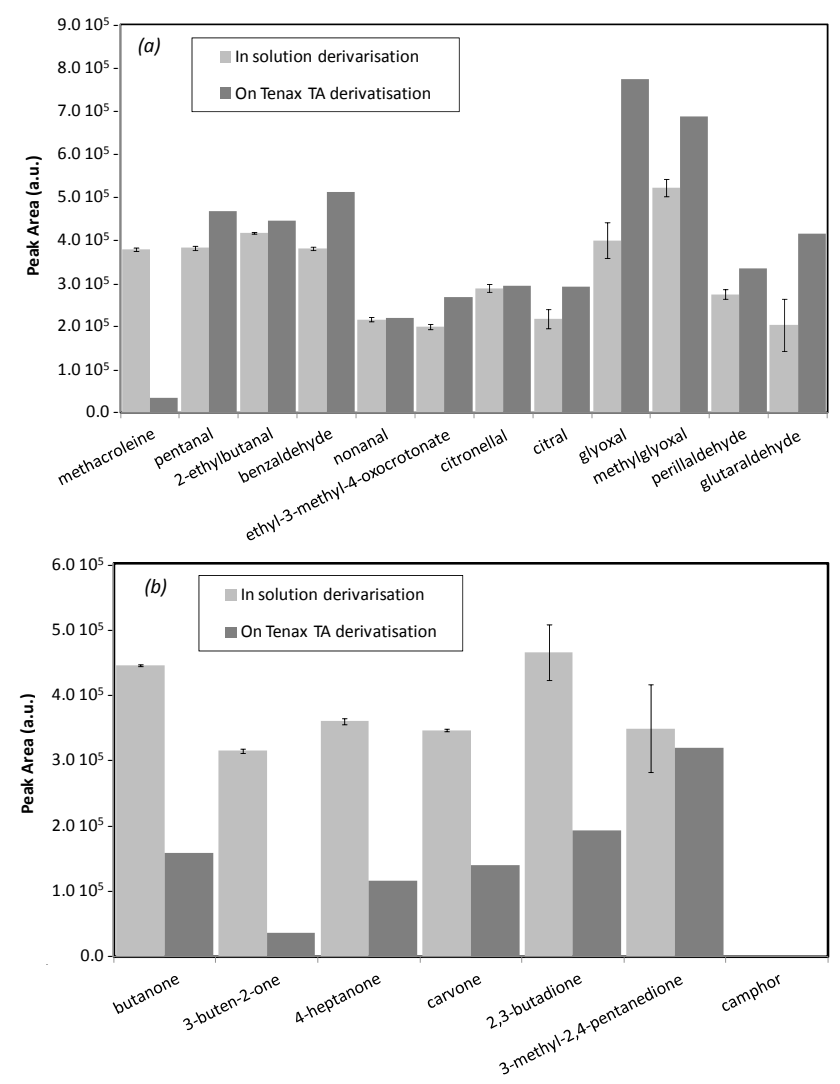

Fig. 7. Comparison of results for in-solution and on-Tenax TA carbonyl compound PFBHA derivatisation: (a) aldehydes derivatisation results, (b) ketone derivatisation results. "Peak Area" refers to FID chromatogram, in area units. Error bars represent \pm one standard deviation determined from four replicates of in-solution derivatisation. On-Tenax TA derivatisation was performed twice. Derivatised camphor was not detected by both methods.

Consequently, a calibration curve for quantification cannot be based on standards prepared from in-solution derivatisation, but has to be made by preparing standards that reproduce real sampling conditions with the method described just above and used for estimating the on-sorbent derivatisation yield estimation (by injecting non-derivatised standard solutions onto PFBHA-coated Tenax TA tubes and exposing them to a wet zero air stream to adjust humidity).

\subsubsection{Breakthrough volumes}

Experiments to determine breakthrough volumes were performed in the CESAM smog chamber. The relative humidity was maintained between 65 and $80 \%$ as it was assumed that a high relative humidity favours breakthrough and consequently may lead to the determination of a lower limit of breakthrough volumes. A temperature of $23^{\circ} \mathrm{C}$ remained constant during the experiment. Samplings were performed on five sampling trains equipped with of two in series identical PFBHA-coated sorbent tubes and operated at a flow rate 
of $100 \mathrm{ml} \mathrm{min}^{-1}$. The experiment was performed within five hours. One sampling was stopped each hour in order to test five sampling volumes.

The breakthrough volume is defined as the air volume required to completely elute a compound through an adsorbent tube (Baltussen et al., 2002). It defines a limit beyond which the trapping is no longer fully efficient and where losses may be encountered. It is defined for a given compound on a given mass of adsorbent and in given environmental conditions of temperature and relative humidity (CEN, 2005). Breakthrough volumes for PFBHA-coated Tenax ${ }^{\circledR}$ TA sorbent tubes were evaluated for a series of five carbonyl compounds. A mixture of methacrolein, hydroxyacetone, octanal, benzaldehyde, carvone and perillaldehyde was injected in the CESAM simulation chamber with respective concentrations of 71,78,121,100,137 and $152 \mu \mathrm{g} \mathrm{m}^{-3}$. Absolute quantification of these species was achieved by the method used for their injection: for each of them, a precisely known pressure (in the range $0.1 \mathrm{mbar}$ ) was applied via a vacuum ramp from a frozen pure standard solution into a bulb of known volume ( $V=1.08321)$. The bulb content was then immediately flushed into the chamber.

For a given compound, the breakthrough volume is reached when measurable quantities of it are found in the second coated tube (back-up tube). Results are shown in Fig. 8. For most of the compounds the breakthrough was found to be satisfactory as it fell in the range needed to sample organics in air. For methacrolein, the breakthrough volume was reached within the first hour, corresponding to a sampling volume smaller than 61 . It was reached between the first and the second hour for hydroxyacetone, corresponding to a breakthrough volume between 6 and 121 . Nevertheless, for the other compounds - octanal, benzaldehyde, carvone and perillaldehyde - the breakthrough volumes were not reached within five hours, corresponding to a breakthrough volume higher than 301 (results are only shown for perillaldehyde, Fig. 8c). Consequently, when the method was applied, a sampling time between one and five hours was used, depending on the atmosphere concentrations but keeping in mind that carbonyls with a number of carbon inferior to five are subjected to breakthrough, i.e. employing back-up tubes if $\mathrm{C}_{1}$ $\mathrm{C}_{4}$ carbonyl compounds require quantification.

\subsubsection{Linearity and detection limits}

Both linearity and detection limits were evaluated from calibration curves. A dilution series of five carbonyl compounds solutions (nine aldehydes and eight ketones) from 5 to $320 \mathrm{ng} \mu \mathrm{l}^{-1}$ was used. Calibration curves were performed from standards reproducing real on-Tenax TA sampling conditions (see Sect. 3.2.3). Results are given in Table 1, including calibration curve slopes, good correlation coefficients (ranging from 0.9883 to 0.9999 ) and satisfactory detection limits. The response linearity was evaluated from a specific $\mathrm{m} / \mathrm{z}$ ion extraction for each compound and was statistically

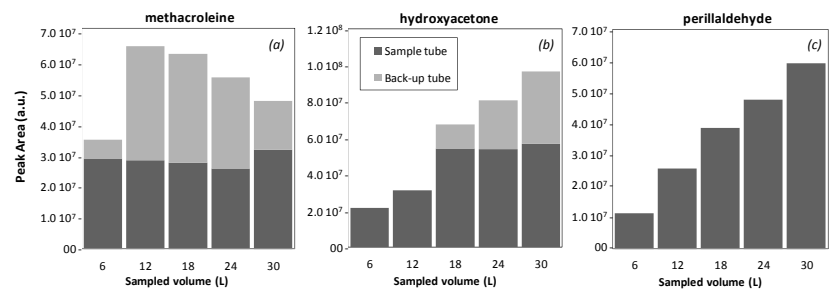

Fig. 8. Evaluation of breakthrough volumes for carbonyl compounds on PFBHA-coated Tenax TA sorbent tubes (a) methacroleine, (b) hydroxyacetone (c) perillaldehyde. 3 "Peak Area" refers to the $m / z 181$ extracted ion chromatogram obtained in the electron ionisation mode, in area units.

validated (Student's t-test). For the negative intercepts obtained for two compounds (citronellal and citral), no explanation could be found. Uncertainties (corresponding to \pm 2 standard errors) are given for a $95 \%$ confidence level. Detection limits (corresponding to 3 times the area noise) are given in absolute mass per sample tube and in concentration units for a sampling volume of 121 (i.e. $100 \mathrm{ml} \mathrm{min}^{-1}$ for $2 \mathrm{~h}$ ). They range from 0.07 to $6 \mathrm{ng}$ per tube, corresponding to concentrations ranging from 6 to $500 \mathrm{ng} \mathrm{m}^{-3}$ (or 1.3 to $81 \mathrm{ppt})$. These detection limits are in the same order of magnitude or better than those obtained by Ho and Yu (2004) and Li et al. (2009), who propose sampling of aldehydes onto PFPH (pentafuorophenyl hydrazine)-coated Tenax TA tubes and obtained detection limits ranging from 0.07 to $6 \mathrm{ng}$ sampled per tube (corresponding to atmospheric concentrations ranging from 6 to $500 \mathrm{ng} \mathrm{m}^{-3}$ for a 121 sample volume).

Compared to the classical 2,4-dinitrophenylhydrazine (DNPH) method involving collection of carbonyls onto DNPH-coated silica cartridges before elution and analysis by HPLC-UV, the detection limits obtained in the present study correspond to a gain of around one order of magnitude (Ho and Yu, 2004). They are in the same order of magnitude or higher than those obtained by Chi et al. (2007), which range from 2 to $9 \mathrm{ng} \mathrm{m}^{-3}$, for a series of mono-carbonyl compounds, by DNPH derivatisation and LC-ESI-MS/MS analysis. The detection limits in the ppt range provided by the method are nevertheless more than satisfactory, considering the concentration levels of carbonyls which can be reached in the atmosphere. As an example, Müller et al. (2006) found concentrations of biogenic carbonyl compounds in a forest region to be about hundreds of ppt.

\subsection{Derivatisation of carboxylic and hydroxyl functions in gas-phase samples}

For the analysis of hydroxyl-bearing gaseous molecules, collection of the gas phase was performed on Tenax ${ }^{\circledR}$ TA sorbent tubes pre-coated with MTBSTFA reagent in order to analyse the carboxyl- and hydroxyl-containing fraction of the gaseous organic matter. This reaction requires significantly different experimental conditions compared to derivatisation 
Table 1. Calibration curves slopes, linearities and detection limits for gaseous carbonyl compounds trapped on PFBHA-coated Tenax TA tubes.

\begin{tabular}{|c|c|c|c|c|c|c|c|}
\hline \multirow[b]{2}{*}{ Standard Compound } & \multirow{2}{*}{$\begin{array}{l}\text { Extracted } \\
\text { ion }(m / z)\end{array}$} & \multirow{2}{*}{$\begin{array}{l}\text { Calibration } \\
\text { curve slope }\end{array}$} & \multirow[b]{2}{*}{ Y-intercept } & \multirow{2}{*}{$\begin{array}{r}\text { Linearity } \\
\qquad\left(R^{2}\right)\end{array}$} & \multicolumn{3}{|c|}{ Detection limits } \\
\hline & & & & & ng tube $e^{-1}$ & $\operatorname{ng~m}^{-3}(*)$ & $\mathrm{ppt}^{(*)}$ \\
\hline \multicolumn{8}{|l|}{ Aldehydes } \\
\hline pentanal & 181 & $(6.8 \pm 0.2) 10^{5}$ & & 0.9993 & 0.3 & 25 & 7.1 \\
\hline 2-ethylbutanal & 239 & $(1.11 \pm 0.03) 10^{5}$ & & 0.9995 & 0.1 & 9 & 2.2 \\
\hline 3-methyl-2-butenal & 264 & $(1.03 \pm 0.01) 10^{5}$ & & 0.9999 & 0.07 & 6 & 1.8 \\
\hline heptanal & 181 & $(5.9 \pm 0.1) 10^{5}$ & & 0.9998 & 0.3 & 25 & 5.4 \\
\hline ethyl-3-methyl-4-oxocrotonate & 140 & $(1.97 \pm 0.02) 10^{4}$ & & 0.9999 & 0.3 & 25 & 4.3 \\
\hline citronellal & 168 & $(7.01 \pm 0.05) 10^{4}$ & $-(1.8 \pm 0.7) 10^{5}$ & 0.9997 & 3 & 250 & 40 \\
\hline citral & 69 & $(1.88 \pm 0.03) 10^{5}$ & $-(1.0 \pm 0.5) 10^{6}$ & 0.9990 & 6 & 500 & 80 \\
\hline perillaldehyde & 164 & $(6.92 \pm 0.06) 10^{4}$ & & 0.9998 & 0.1 & 9 & 1.5 \\
\hline glutaraldehyde & 181 & $(9.7 \pm 0.6) 10^{5}$ & & 0.9952 & 0.1 & 9 & 2.2 \\
\hline \multicolumn{8}{|l|}{ Ketones } \\
\hline 3-penten-2-one & 264 & $(3.21 \pm 0.07) 10^{4}$ & & 0.9997 & 0.1 & 9 & 2.6 \\
\hline 3-hydroxy-3-methyl-2-butanone & 181 & $(1.1 \pm 0.2) 10^{5}$ & & 0.9883 & 1 & 84 & 20 \\
\hline 2-hexanone & 181 & $(7.5 \pm 0.6) 10^{4}$ & & 0.9962 & 2 & 167 & 41 \\
\hline 4-heptanone & 128 & $(1.08 \pm 0.05) 10^{4}$ & & 0.9988 & 0.9 & 75 & 16 \\
\hline 5-hydroxy-2-pentanone & 279 & $(1.89 \pm 0.04) 10^{3}$ & & 0.9992 & 2 & 167 & 40 \\
\hline$(+)$-dihydrocarvone & 93 & $(3.91 \pm 0.08) 10^{4}$ & & 0.9997 & 1 & 84 & 14 \\
\hline carvone & 304 & $(4.0 \pm 0.4) 10^{4}$ & & 0.9914 & 0.09 & 8 & 1.3 \\
\hline dimethylglyoxal & 476 & $(6.6 \pm 0.4) 10^{2}$ & & 0.9970 & 7,0 & 584 & 166 \\
\hline 3-methyl-2,4-pentanedione & 181 & $(4.2 \pm 0.2) 10^{5}$ & & 0.9983 & 0.4 & 34 & 7.3 \\
\hline \multicolumn{8}{|l|}{ Keto-aldehydes } \\
\hline methylglyoxal & 181 & $(1.7 \pm 0.4) 10^{6}$ & & 0.9742 & 0.05 & 5 & 1.7 \\
\hline 4-oxopentanal & 181 & $(6.7 \pm 0.2) 10^{5}$ & & 0.9997 & 0.02 & 2 & 0.5 \\
\hline
\end{tabular}

(*) Given 1 for a sampling volume of 121 .

with PFBHA and is known to be sensitive to different parameters. In particular, it is sensitive to humidity and, hence, required the development of a specific protocol.

\subsubsection{Sorbent coating and post-sampling derivatisation protocol}

Similar to the PFBHA procedure, Tenax TA coating with MTBSTFA was performed without any solvent by vaporisation of $0.3 \mu \mathrm{l}$ pure MTBSTFA (+1\% TBDMS) under a heated helium stream $\left(270^{\circ} \mathrm{C}, 30 \mathrm{ml} \mathrm{min}^{-1}\right)$ for only $8 \mathrm{~min}$. A dry purge of $2 \mathrm{~min}$ was applied before injection of MTBSTFA to remove traces of water in the sorbent tube. However, as previously mentioned, MTBSTFA and MTBSTFA-derivatised compounds are prone to hydrolysis, especially during sampling of humid ambient or simulated atmospheres. Consequently, in order to promote derivatisation, and considering the hydrophobic nature of Tenax TA, samples were re-exposed to MTBSTFA after sampling: samples were opened, $0.3 \mu \mathrm{l}$ of pure MTBSTFA ( $+1 \%$ TBDMS) was applied at each end of the sampling tubes and the reclosed samples were left in a furnace at $60^{\circ} \mathrm{C}$ for $5 \mathrm{~h}$. After cooling to room temperature, the samples had to be rapidly analysed by TD/GC/MS within $5 \mathrm{~h}$ to prevent decomposition of the derivatives.

\subsubsection{Derivatisation yield and standards preparation}

Derivatisation yields were estimated comparing in-solution derivatisation and on-Tenax TA derivatisation. In-solution derivatisation was performed at room temperature within two hours by adding a molar excess of MTBSTFA (corresponding to ten times the molar concentration of derivatisable functions) to the non-derivatised solution in acetonitrile $\left(80 \mathrm{ng} \mathrm{l}^{-1}\right)$. Derivatised solutions were then evaporated under a heated helium stream and trapped onto clean Tenax TA tubes before TD-GC-FID analysis. On-Tenax TA derivatisation was performed by preparing standard Tenax TA tubes. Clean Tenax TA tubes were spiked with the non-derivatised solution directly onto the Tenax TA adsorbent with a microsyringe. Spiked tubes were placed 3 min under a heated helium stream $\left(270^{\circ} \mathrm{C}, 30 \mathrm{ml} \mathrm{min}^{-1}\right)$ in order to elute compounds on the Tenax surface and better represent a real sampling. Tubes, thereafter referred as carboxyls/hydroxyls 

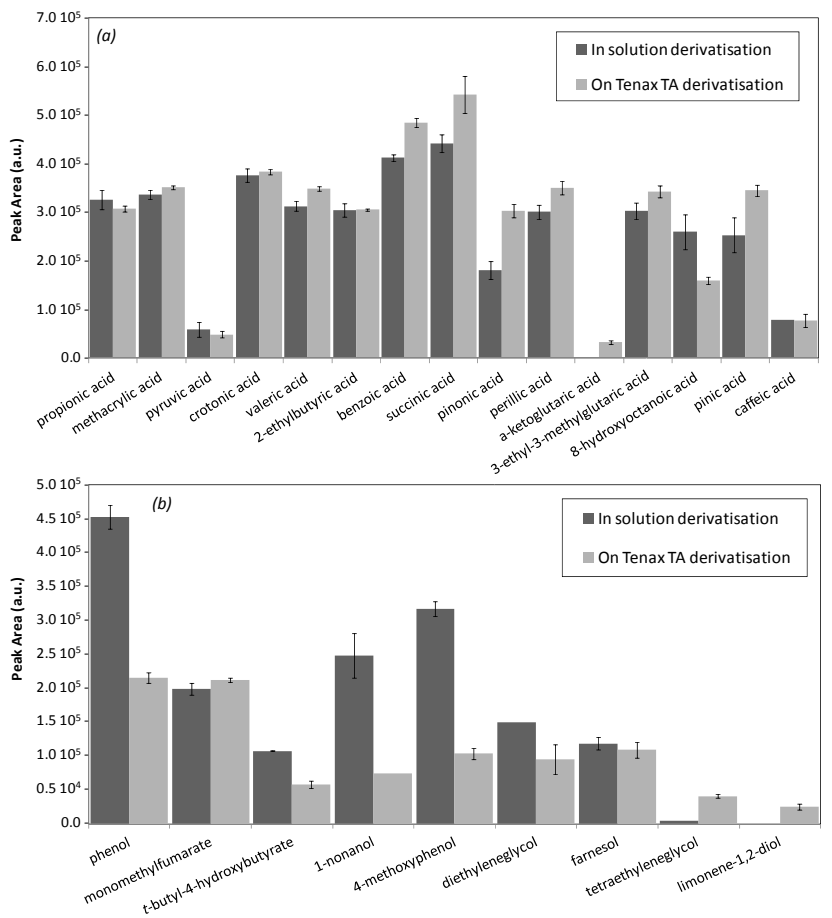

Fig. 9. Comparison of in-solution and on-Tenax TA carboxyl/hydroxyl compound MTBSTFA-derivatisation: (a) carboxylic acids derivatisation results, (b) hydroxyl compounds derivatisation results. "Peak Area" refers to FID chromatogram, in area units. Error bars represent \pm one standard deviation determined from three replicates for on-Tenax TA derivatisation and from two replicates for in-solution derivatisation (no error bar indicates only one replicate).

standard tubes, were then derivatised as previously presented for samples (see Sect. 3.3.1) and analysed by TD-GC-FID. The comparison of the results is shown in Fig. 9. A good agreement was found between in-solution and on-Tenax TA derivatisation yields for the acids, whereas significant discrepancies were observed for hydoxyl-bearing species. This is especially true for some alcohols such as phenol, $t$-butyl-4-hydroxy butyrate, 1-nonanol, 4-methoxyphenol for which decreases larger than $45 \%$ in derivatisation yield were observed.

Thus, despite the low derivatisation yields for some compounds, satisfactory on-Tenax TA derivatisation repeatability was observed, allowing quantification.

Consequently, calibration curves for quantification cannot be based on standards prepared from in-solution derivatisation, but instead have to be constructed by preparing standards reproducing real sampling conditions with the method described just above and used for estimating the on-sorbent derivatisation yield.

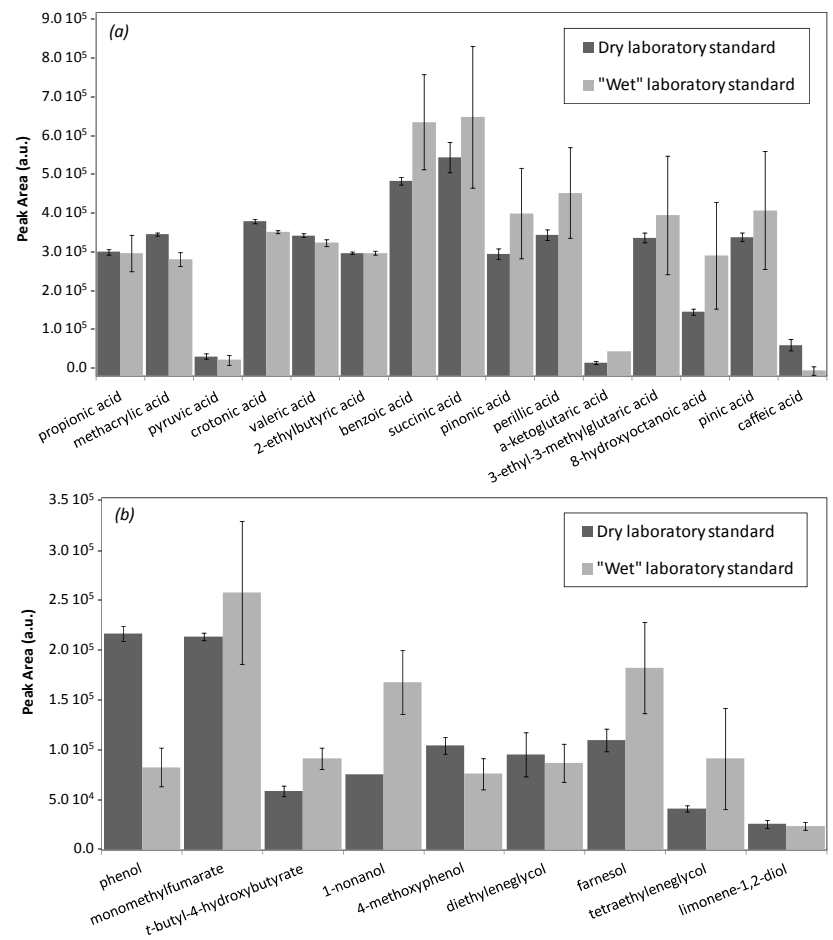

Fig. 10. Humidity influence on on-Tenax TA carboxyl/hydroxyl compounds MTBSTFA derivatisation: (a) carboxylic acids derivatisation results, (b) hydroxyl compounds derivatisation results. "Peak Area" refers to FID chromatogram, in area units. Error bars represent \pm one standard deviation determined from three replicates.

\subsubsection{Humidity influence}

The influence of humidity on the derivatisation process was evaluated by humidifying carboxyl/hydroxyl standard tubes before the post-derivatisation process. Two series of three carboxyls/hydroxyls standard tubes were prepared by spiking one $\mu \mathrm{l}$ of a non-derivatised solution at a concentration of $80 \mathrm{ng} \mathrm{hl}^{-1}$. Wet zero air $(50 \% \mathrm{RH})$ was sampled for thirty minutes at a flow rate of $100 \mathrm{ml} \mathrm{min}^{-1}$ for the first series, while the second series remained closed and in dry conditions. After the post-derivatisation process, both series were analysed by TD-GC-FID. The results are shown in Fig. 10, revealing no significant discrepancies between wet and dry standards (except for nonanol and phenol) despite a lower repeatability for some compounds in wet conditions. Consequently, the post-derivatisation process is assumed to overcome the influence of humidity on the analytical protocol. Hence, the calibration can be performed using dry carboxyls/hydroxyls standard tubes.

From the humidified series of three standards, an estimation of the method repeatability can be given. The mean standard deviation/mean ratio was $25 \%$ for all compounds, ranging from 12 ( $t$-butyl-4-hydroxybutyrate) to $55 \%$ (ethylene glycol) for alcohols and from 1 (crotonic acid) to $79 \%$ (caffeic acid) for carboxylic acids. 
Table 2. Breakthrough data, in percentage corresponding to the back-up tube/sample tube ratio for the quantified compound, for a series of hydroxyl 1 and carboxyl compounds identified from an isoprene photo-oxidation experiment vs. compound type, molar mass, MTBSTFAderivatised functional groups and retention times (indicatives).

\begin{tabular}{|c|c|c|c|c|}
\hline Identified compound & Compound type & $\begin{array}{r}\text { Molecular } \\
\text { Weight (MTBSTFA- } \\
\text { derivatisated } \\
\text { functional groups) }\end{array}$ & $\mathrm{RT}(\min )$ & Breakthrough $(\%)$ \\
\hline methacrylic acid & $\mathrm{C}_{4}$ mono acid & $86(1)$ & 11,87 & 6 \\
\hline crotonic acid & $\mathrm{C}_{4}$ mono acid & $86(1)$ & 12,80 & 25 \\
\hline valeric acid & $\mathrm{C}_{5}$ mono acid & $102(1)$ & 13,36 & 3 \\
\hline 3-ethylbutyric acid & $\mathrm{C}_{6}$ mono acid & $116(1)$ & 13,75 & 21 \\
\hline 3-methylpentanoic acid & $\mathrm{C}_{6}$ mono acid & $116(1)$ & 14,68 & 52 \\
\hline levulinic acid & $\mathrm{C}_{5}$ keto mono acid & $116(1)$ & 15,58 & $<1$ \\
\hline heptanoic acid & $\mathrm{C}_{7}$ mono acid & $130(1)$ & 15,99 & 0 \\
\hline 1-methylcyclohexanecarboxylic acid ${ }^{(*)}$ & $\mathrm{C}_{8}$ mono acid & $142(1)$ & 16,10 & 0 \\
\hline glycolic acid & $\mathrm{C}_{2}$ hydroxy acid & $76(2)$ & 16,37 & $<1$ \\
\hline 2-hydroxypropanoic acid & $\mathrm{C}_{3}$ hydroxy acid & $90(2)$ & 17,25 & $<1$ \\
\hline oxalic acid & $\mathrm{C}_{2}$ di acid & $90(2)$ & 17,92 & $<1$ \\
\hline maleic acid & $\mathrm{C}_{4}$ di acid & $116(2)$ & 20,25 & 0 \\
\hline succinic acid & $\mathrm{C}_{4}$ di acid & $118(2)$ & 20,41 & $<1$ \\
\hline glutaric acid & $\mathrm{C}_{5} \mathrm{di}$ acid & $132(2)$ & 21,45 & 0 \\
\hline glycerol & $\mathrm{C}_{3}$ tri alcohol & $92(3)$ & 21,59 & 0 \\
\hline 2,3-dihydroxypropanoic acid & $\mathrm{C}_{3}$ di hydroxy mono acid & $106(3)$ & 22,34 & 0 \\
\hline adipic acid & $\mathrm{C}_{6}$ di acid & $146(2)$ & 22,56 & 0 \\
\hline suberic acid & $\mathrm{C}_{8}$ di acid & $174(2)$ & 24,48 & 0 \\
\hline 2-hydroxypentanedioic acid & $\mathrm{C}_{5}$ hydroxy di acid & $148(3)$ & 31,23 & 0 \\
\hline
\end{tabular}

(*) Identified from a limonene ozonolysis experiment (see Sect. 4).

\subsubsection{Breakthrough volumes}

Given the difficulty to generate stable atmospheres of hydroxyl and carboxyl compounds with low vapour pressures, precise breakthrough volumes could not be determined. An evaluation of the breakthrough of MTBSTFA-coated sorbent tubes is given here as breakthrough data for a series of carboxyl and hydroxyl compounds generated in an isoprene photo-oxidation experiment. This experiment was selected because it produced a wider range of volatile oxygenated species compared to the limonene ozonolysis experiment, and was conducted in the EUPHORE chamber. The initial isoprene concentration was $55 \mathrm{ppb}$ for an initial $\mathrm{H}_{2} \mathrm{O}_{2}$ concentration of $4 \mathrm{ppm}$. The relative humidity and temperature were $25 \%$ and $303 \mathrm{~K}$, respectively, during sampling time, after exposing the chamber to sunlight and system stabilisation. Sampling was performed onto two in series MTBSTFA precoated Tenax TA sorbent tubes at a flow rate of $100 \mathrm{ml} \mathrm{min}^{-1}$ during two hours (sampled volume: 121). The second tube (following air flux) was employed as a "back-up tube" to collect the compounds that were not completely trapped onto the first one. The results are shown in Table 2, which gives an evaluation of the breakthrough in \%, corresponding to the ratio between the amount of compound measured in the backup tube and that measured in the sample tube for each examined compounds. No breakthrough could be observed for most examined compounds, especially for those bearing several functionalities and/or displaying a carbon skeleton with more than five carbons.

It must be pointed out that the chamber background presented contaminations, which were responsible for the detection of compounds with more than five carbons from this isoprene photo-oxidation experiment, were not subtracted here since the purpose was to determine the breakthrough volume and not to explain isoprene oxidation pathways. All the detected compounds were consequently taken into account for the evaluation of the breakthrough, contaminations and isoprene oxidation products.

Significant breakthrough was only observed for monofunctionalised compounds with a carbon number less than seven. If these compounds are targeted, the use of back-up tubes is thus required. Poly-functionalised compounds, even with only two carbons, do not seem to be affected by breakthrough under our experimental conditions. Their breakthrough volumes are consequently estimated to be greater than 121 . When performing measurements in the same sampling conditions of sample volume, sampling flow rate, humidity and temperature, the use of back-up tubes is thus not required. When performing measurements in different conditions, the determination of breakthrough volumes or the use of back-up tubes is recommended. 
Table 3. Calibration curves slopes, linearities and detection limits for gaseous carbonyl compounds trapped on PFBHA-coated Tenax TA tubes.

\begin{tabular}{|c|c|c|c|c|c|c|}
\hline \multirow[b]{2}{*}{ Standard Compound } & \multirow{2}{*}{$\begin{array}{l}\text { Extracted } \\
\text { ion }(m / z)\end{array}$} & \multirow{2}{*}{$\begin{array}{l}\text { Calibration } \\
\text { curve slope }\end{array}$} & \multirow{2}{*}{$\begin{array}{r}\text { Linearity } \\
\qquad\left(R^{2}\right)\end{array}$} & \multicolumn{3}{|c|}{ Detection limits } \\
\hline & & & & ng tube $e^{-1}$ & $\operatorname{ng~m}^{-3(*)}$ & $\operatorname{ppt}^{(*)}$ \\
\hline \multicolumn{7}{|l|}{ Alcohols } \\
\hline 5-hydroxy-2-pentanone & 75 & $(7 \pm 2) \times 10^{4}$ & 0.9769 & 0.5 & 42 & 10 \\
\hline hydroxycyclohexanone & 171 & $(1.7 \pm 0.4) \times 10^{3}$ & 0.9576 & 5 & 417 & 89 \\
\hline$t$-butyl-4-hydroxybutyrate & 161 & $(9 \pm 2) \times 10^{4}$ & 0.9830 & 0.2 & 17 & 2.6 \\
\hline (S)-3-butene-1,2-diol & 259 & $(9 \pm 2) \times 10^{2}$ & 0.9578 & 10 & 834 & 232 \\
\hline 1-nonanol & 201 & $(1.1 \pm 0.3) \times 10^{5}$ & 0.9632 & 0.08 & 7 & 1.2 \\
\hline farnesol & 279 & $(3.7 \pm 0.6) \times 10^{3}$ & 0.9840 & 3 & 250 & 28 \\
\hline \multicolumn{7}{|l|}{ Carboxylic acids } \\
\hline valeric acid & 75 & $(2.77 \pm 0.08) \times 10^{5}$ & 0.9989 & 0.09 & 8 & 1.9 \\
\hline levulinic acid & 75 & $(1.8 \pm 0.1) \times 10^{5}$ & 0.9977 & 0.08 & 7 & 1.5 \\
\hline heptanoic acid & 75 & $(1.83 \pm 0.05) \times 10^{5}$ & 0.9983 & 0.05 & 5 & 0.9 \\
\hline monomethyl fumarate & 187 & $(3.6 \pm 0.3) \times 10^{5}$ & 0.9941 & 0.07 & 6 & 1.1 \\
\hline 6-oxoheptanoic acid & 117 & $(2.3 \pm 0.2) \times 10^{5}$ & 0.9926 & 0.8 & 67 & 11 \\
\hline 2,2-dimethyl-3-hydroxypropionic acid & 147 & $(1.2 \pm 0.2) \times 10^{5}$ & 0.9811 & 0.5 & 42 & 8.7 \\
\hline succinic acid & 289 & $(3.4 \pm 0.2) \times 10^{5}$ & 0.9956 & 0.07 & 6 & 1.2 \\
\hline cis-pinonic acid & 171 & $(3.2 \pm 0.3) \times 10^{5}$ & 0.9941 & 0.2 & 17 & 2.3 \\
\hline perillic acid & 223 & $(3.9 \pm 0.3) \times 10^{5}$ & 0.9947 & 0.09 & 8 & 1.2 \\
\hline 8-hydroxyoctanoic acid & 331 & $(5.6 \pm 0.7) \times 10^{4}$ & 0.9861 & 0.2 & 17 & 2.6 \\
\hline D-malic acid & 419 & $(1.1 \pm 0.1) \times 10^{5}$ & 0.9872 & 0.8 & 67 & 12 \\
\hline pinic acid & 171 & $(2.7 \pm 0.2) \times 10^{5}$ & 0.9913 & 0.3 & 25 & 3.3 \\
\hline 4-oxoheptanedioic acid & 345 & $(1.9 \pm 0.3) \times 10^{5}$ & 0.9746 & 2 & 167 & 23 \\
\hline 3-carboxyhexanedioic acid & 475 & $(5 \pm 2) \times 10^{4}$ & 0.9368 & 2 & 167 & 21 \\
\hline
\end{tabular}

${ }^{(*)}$ Given for a sampling volume of 121 .

\subsubsection{Linearity and detection limits}

Both linearity and detection limits were evaluated from calibration curves. A dilution series of five hydroxyl compounds and organic acid solutions (six alcohols and fourteen organic acids) from 5 to $320 \mathrm{ng} \mathrm{\mu l}^{-1}$ was used. Calibration curves were performed from standards reproducing real on-Tenax TA sampling conditions (see Sect. 3.3.2). $1 \mu$ of carbonyl compound standard solutions were applied onto Tenax TA tubes and subsequently derivatised with MTBSTFA at $60^{\circ} \mathrm{C}$ for $5 \mathrm{~h}$. Results are shown in Table 3. Response linearity for all compounds was statistically validated (Student's t-test) and uncertainties (corresponding to \pm 2 standard errors) are given for a $95 \%$ confidence level. Detection limits (corresponding to 3 times the area noise) are given in absolute mass per sample tube and in concentration units for a sampling volume of 121 (i.e. $100 \mathrm{ml} \mathrm{min}^{-1}$ for $2 \mathrm{~h}$ ). They range from 0.05 to $10 \mathrm{ng}$ per tube and from 5 to $830 \mathrm{ng} \mathrm{m}^{-3}$. These detection limits are lower than those obtained by $\mathrm{Wu}$ et al. (2008) for the analysis of volatile fatty acids without derivatisation and in the same order of magnitude or lower than those obtained by Chiappini et al. (2006) or Pietrogrande et al. (2010). The detection limits in the latter studies ranged from 1.2 to $6.8 \mathrm{ng}$ per GC/MS injection for mono- and dicarboxylic acids in the aerosol phase with prior derivatisation in $\mathrm{CO}_{2}$ supercritical fluid or in solution. The detection limits obtained in the present study, ranging from 1 to $232 \mathrm{ppt}$, are more than satisfactory to measure hydroxyl and carboxyl compounds at lower ambient concentration levels. As an example, the concentration levels of dicarboxylic acids measured by Legrand et al. (2005) at altitude sites in France are a few tens of $\mathrm{ppb}$.

\subsection{Derivatisation of carbonyl functions in particulate phase samples}

Collection of the particulate phase for the analysis of carbonyl compounds was carried out on $47 \mathrm{~mm}$ quartz fibre filters (see Sect. 2.1.4) at a typical flow rate of $1 \mathrm{~m}^{3} \mathrm{~h}^{-1}$ $\left(16.71 \mathrm{~min}^{-1}\right)$ and was done simultaneously with sampling of the gas phase. The PFBHA post-sampling derivatisation process was performed by sample introduction into stainless-steel tubes suitable for thermal desorption and exposition of the sample to the PFBHA reagent. The humidity influence on the particulate-phase derivatisation process 
Table 4. Calibration curves slopes, linearities and detection limits for particulate carbonyl compounds trapped on quartz fibres filters and PFBHA-derivatised.

\begin{tabular}{|c|c|c|c|c|c|c|}
\hline \multirow[b]{2}{*}{ Standard Compound } & \multirow{2}{*}{$\begin{array}{l}\text { Extracted } \\
\text { ion }(m / z)\end{array}$} & \multirow{2}{*}{$\begin{array}{l}\text { Calibration } \\
\text { curve slope }\end{array}$} & \multirow[b]{2}{*}{ Y-intercept } & \multirow{2}{*}{$\begin{array}{r}\text { Linearity } \\
\qquad\left(R^{2}\right)\end{array}$} & \multicolumn{2}{|c|}{ Detection limit } \\
\hline & & & & & ng filter ${ }^{-1}$ & $\operatorname{ng~m}^{-3(*)}$ \\
\hline \multicolumn{7}{|l|}{ Aldehydes } \\
\hline pentanal & 181 & $(4.9 \pm 0.2) \times 10^{5}$ & & 0.9986 & 0.2 & 0.1 \\
\hline 2-ethylbutanal & 239 & $(7.5 \pm 0.07) \times 10^{4}$ & & 0.9999 & 0.04 & 0.02 \\
\hline 3-methyl-2-butenal & 264 & $(4.3 \pm 0.2) \times 10^{4}$ & & 0.9994 & 0.09 & 0.05 \\
\hline heptanal & 181 & $(2.4 \pm 0.2) \times 10^{4}$ & & 0.9968 & 3 & 2 \\
\hline ethyl-3-methyl-4-oxocrotonate & 140 & $(7 \pm 3) \times 10^{3}$ & & 0.8625 & 0.9 & 0.5 \\
\hline citronellal & 168 & $(7 \pm 2) \times 10^{3}$ & & 0.9532 & 6 & 3 \\
\hline citral & 69 & $(1.2 \pm 0.4) \times 10^{4}$ & & 0.9381 & 2 & 1 \\
\hline perillaldehyde & 164 & $(1.0 \pm 0.2) \times 10^{3}$ & & 0.9793 & 5 & 3 \\
\hline glutaraldehyde & 181 & $(4 \pm 3) \times 10^{3}$ & & 0.7846 & 15 & 8 \\
\hline \multicolumn{7}{|l|}{ Ketones } \\
\hline 3-penten-2-one & 264 & $(2.1 \pm 0.8) \times 10^{4}$ & & 0.8702 & 0.2 & 0.1 \\
\hline 3-hydroxy-3-methyl-2-butanone & 181 & $(1.0 \pm 0.4) \times 10^{4}$ & & 0.889 & 4 & 2 \\
\hline 2-hexanone & 181 & $(1.07 \pm 0.02) \times 10^{5}$ & & 0.9998 & 0.4 & 0.2 \\
\hline 4-heptanone & 128 & $(2.72 \pm 0.06) \times 10^{4}$ & & 0.9996 & 0.2 & 0.1 \\
\hline 5-hydroxy-2-pentanone & 279 & $(8.8 \pm 0.2) \times 10^{1}$ & $-(7.0 \pm 0.4) \times 10^{3}$ & 0.9999 & 120 & 60 \\
\hline$(+)$-dihydrocarvone & 93 & $(6.3 \pm 0.4) \times 10^{3}$ & $-(1.2 \pm 0.7) \times 10^{5}$ & 0.9999 & 23 & 12 \\
\hline carvone & 304 & $(1.4 \pm 0.2) \times 10^{4}$ & & 0.9848 & 0.2 & 0.1 \\
\hline dimethylglyoxal & 476 & $(2.1 \pm 0.3) \times 10^{4}$ & & 0,9931 & 0.2 & 0.1 \\
\hline 3-methyl-2,4-pentanedione & 181 & $(6 \pm 2) \times 10^{4}$ & & 0.9131 & 2 & 1 \\
\hline \multicolumn{7}{|l|}{ Keto-aldehydes } \\
\hline methylglyoxal & 181 & $(5 \pm 2) \times 10^{5}$ & & 0,9811 & 0.08 & 0.04 \\
\hline 4-oxopentanal & 181 & $(1.79 \pm 0.07) \times 10^{5}$ & & 0.9984 & 0.04 & 0.02 \\
\hline
\end{tabular}

(*)Given for a sampling volume of $2 \mathrm{~m}^{3}$.

was expected to be similar to that observed for gas-phase derivatisation (Sect. 3.2.2).

\subsubsection{Post-sampling derivatisation protocol}

The $47 \mathrm{~mm}$ sample filter was divided in four parts and was introduced into a clean stainless steel thermal desorption tube. After the introduction of each quarter, $2 \mu$ of a saturated PFBHA solution $\left(27 \mathrm{mg} \mathrm{ml}^{-1}\right.$, 90/10 acetonitrile/ultrapure water mixture) was applied onto the filter part. A glass bulb with eight outlets was then used to expose in-tube samples to a saturated PFBHA aqueous solution for $40 \mathrm{~h}$. This duration was expected to be sufficient to impregnate a rolled filter with PFBHA and was convenient for protocol organisation. From one end, the filter sample tubes were connected to the bulb outlets while the other end was kept closed. $1 \mathrm{ml}$ of ultrapure water was introduced in the bulb and stirred (500 rounds per min). $90 \mathrm{mg}$ of pure and solid PFBHA was then added to the water. The bulb was closed and the system was kept at room temperature. After $20 \mathrm{~h}$, filter sample tubes were disconnected, reversed, reconnected by the other end and left for
$20 \mathrm{~h}$ again. Filter sample tubes were then definitely disconnected, closed and kept at room temperature for a minimum of 5 days before analysis.

\subsubsection{Standard preparation, linearity and detection limits}

Standards used to construct calibration curves were prepared and derivatised in the same way as sample filters. Clean quartz fibre filters were introduced into empty stainless steel desorption tubes with application of a PFBHA saturated solution, spiked with $1 \mu \mathrm{l}$ of standard carbonyl compound so-

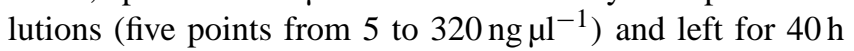
connected to a stirred glass bulb containing $1 \mathrm{ml}$ of a PFBHA saturated aqueous solution (with tube reversion after $20 \mathrm{~h}$ ) at room temperature. Both linearity and detection limits were evaluated. Results are shown in Table 4, giving for each compound the calibration curve slopes, the correlation coefficients (which are generally good, most are ranging from 0.9131 and 0.9999 , except for three compounds displaying 
an $R^{2}$ value ranging from 0.7846 to 0.8890 ), and the detection limits, which are satisfactory.

The response linearity for all compounds was statistically validated (Student's t-test) and uncertainties (corresponding to \pm 2 standard errors) are given for a $95 \%$ confidence level. Detection limits (corresponding to 3 times the area noise) are given in absolute mass per filter and in concentration units for a sampling volume of $2 \mathrm{~m}^{3}$ (i.e. $16.71 \mathrm{~min}^{-1}$ for $2 \mathrm{~h})$. These detection limits, ranging from 0.04 to $120 \mathrm{ng}$ per filter (corresponding to an atmospheric concentration of 0.02 and $60 \mathrm{ng} \mathrm{m}^{-3}$ for a $2 \mathrm{~m}^{3}$ sample volume), are more than sufficient to measure carbonyl compounds in the atmosphere where their concentrations are in the same order of magnitude (Liggio and McLaren, 2003).

\subsection{Derivatisation of carboxylic and hydroxyl functions in particulate-phase samples}

Collection of the particulate phase for the analysis of carboxyl and hydroxyl compounds was performed on $47 \mathrm{~mm}$ Teflon-quartz fibres filters (see Sect. 2.1.4) at a typical flow rate of $1 \mathrm{~m}^{3} \mathrm{~h}^{-1}\left(16.71 \mathrm{~min}^{-1}\right)$ simultaneously with gas-phase sampling. The MTBSTFA post-sampling derivatisation procedure was performed after sample introduction into stainless-steel tubes that are suitable for thermal desorption and exposition of samples to pure MTBSTFA (+1\% TBDMS).

\subsubsection{Post-sampling derivatisation protocol}

The $47 \mathrm{~mm}$ sample filter was divided in four parts and was introduced into a clean stainless steel thermal desorption tube. MTBSTFA was not applied directly onto the filter. $10 \mu \mathrm{l}$ of pure MTBSTFA $(+1 \%$ TBDMS) were introduced on the bottom of one tube cap and the sample filter tube was closed in vertical position above the MTBSTFA (cf. Fig. 11). The filter was exposed to MTBSTFA at room temperature during $24 \mathrm{~h}$. The filter sample tube was then directly analysed by TD-GC/MS within $5 \mathrm{~h}$.

\subsubsection{Humidity influence and standard preparation}

As for gaseous compounds derivatisation on Tenax TA tubes, humidity was expected to influence the on-filter MTBSTFA derivatisation process; therefore, Teflon-quartz filters were chosen to reduce moisture loading during wet air sampling. Nevertheless, in order to evaluate the influence of this moisture loading on the derivatisation process, response factors of a series of standard compounds were compared for dry and pre-humidified Teflon-quartz filters. Five point calibration curves (from 5 to $320 \mathrm{ng} \mathrm{\mu l}^{-1}$ ) were constructed using filters spiked with standards and prepared and derivatised in the same way as sample filters. Wet Teflon-quartz filters were humidified by sampling wet zero air $(50 \% \mathrm{RH})$ at a flow rate of $71 \mathrm{~min}^{-1}$ for $2 \mathrm{~h}$. Clean and dry or wet filters were introduced into empty stainless-steel desorption tubes and spiked

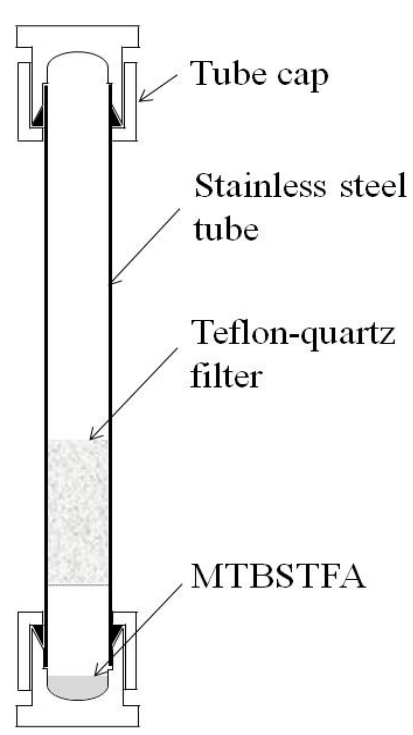

Fig. 11. Particulate-phase MTBSTFA derivatisation scheme.

with standard solutions. They were subsequently derivatised by exposition to MTBSTFA for $24 \mathrm{~h}$ at room temperature. The comparison of the results for compound response factors are given in Fig. 12. Surprisingly, the response factors were significantly higher for those derivatised onto humidified filters for 15 standard compounds of the 18 tested. Moreover, for keto-acids (6-oxoheptanoic acid and cis-pinonic acid), di-acids (succinic acid and pinic acid) and malic acid, the compound responses became linear compared to their responses on dry filters (not mentioned in Fig. 12). The reason why humidity positively influences on-filter derivatisation is not clear. It might be explained by competition phenomena between water and polar compounds to form bonds with the quartz surface. In this case, moisture loading may positively affect both the derivatisation reaction and the desorption capacity limiting the adsorption of polar compounds on the filter surface. Anyway, the positive influence of moisture loading onto filters has two main consequences on the method: (1) it is not necessary to dry sample filters before derivatisation with MTBSTFA, and (2) calibration curves have to be contructed using humidified Teflon-quartz filters.

\subsubsection{Linearity and detection limits}

Both linearity and detection limits were evaluated from calibration curves that were previously used for the evaluation of the humidity influence. The results are shown in Table 5, giving for each compound the calibration curve slopes, correlation coefficients (which are satisfactory and range from 0.9433 to 0.9999 ), and detection limits, which are low.

Response linearity was statistically validated (Student's ttest) and uncertainties (corresponding to \pm 2 standard errors) are given for a $95 \%$ confidence level. Detection limits (corresponding to 3 times the area noise) are given in absolute mass 
Table 5. Calibration curves slopes, linearities and detection limits for particulate hydroxyl compounds and organic acids trapped on Teflonquartz 1 fibres filters and MTBSTFA-derivatised.

\begin{tabular}{|c|c|c|c|c|c|}
\hline \multirow[b]{2}{*}{ Standard Compound } & \multirow{2}{*}{$\begin{array}{l}\text { Extracted } \\
\text { ion }(m / z)\end{array}$} & \multirow{2}{*}{$\begin{array}{l}\text { Calibration } \\
\text { curve slope }\end{array}$} & \multirow{2}{*}{$\begin{array}{r}\text { Linearity } \\
\qquad\left(R^{2}\right)\end{array}$} & \multicolumn{2}{|c|}{ Detection Limits } \\
\hline & & & & ng filter ${ }^{-1}$ & $\mathrm{ng} \mathrm{m}^{-3(*)}$ \\
\hline \multicolumn{6}{|l|}{ Alcohols } \\
\hline 5-hydroxy-2-pentanone & 75 & $(1.0 \pm 0.2) \times 10^{5}$ & 0.9837 & 0.8 & 0.4 \\
\hline hydroxycyclohexanone & 171 & $(1.8 \pm 0.3) \times 10^{4}$ & 0.9791 & 0.4 & 0.2 \\
\hline$t$-butyl-4-hydroxybutyrate & 161 & $(2.21 \pm 0.08) \times 10^{5}$ & 0.9988 & 0.04 & 0.02 \\
\hline (S)-3-butene-1,2-diol & 259 & $(8.5 \pm 0.4) \times 10^{4}$ & 0.9967 & 0.04 & 0.02 \\
\hline 1-nonanol ${ }^{a}$ & 201 & $(2.9 \pm 0.5) \times 10^{5}$ & 0.9633 & 0.04 & 0.02 \\
\hline farnesol & 279 & $(3.6 \pm 0.2) \times 10^{4}$ & 0.9979 & 0.4 & 0.2 \\
\hline \multicolumn{6}{|l|}{ Carboxylic acids } \\
\hline valeric acid & 75 & $(8.6 \pm 0.3) \times 10^{4}$ & 0.9990 & 0.7 & 0.4 \\
\hline levulinic acid ${ }^{b}$ & 75 & $(1.2 \pm 0.4) \times 10^{5}$ & 0.9433 & 0.9 & 0.5 \\
\hline heptanoic acid & 75 & $(1.5 \pm 0.2) \times 10^{5}$ & 0.9582 & 1.0 & 0.5 \\
\hline monomethyl fumarate & 187 & $(3.52 \pm 0.05) \times 10^{5}$ & 0.9999 & 0.2 & 0.1 \\
\hline 6-oxoheptanoic acid & 117 & $(2.15 \pm 0.08) \times 10^{5}$ & 0.9990 & 0.3 & 0.2 \\
\hline 2,2-dimethyl-3-hydroxypropionic acid & 147 & $(3.5 \pm 0.2) \times 10^{5}$ & 0.9966 & 0.2 & 0.1 \\
\hline succinic acid & 289 & $(5 \pm 2) \times 10^{5}$ & 0,8861 & 0.02 & 0.01 \\
\hline cis-pinonic acid & 171 & $(3.4 \pm 0.5) \times 10^{5}$ & 0.9863 & 0.2 & 0.1 \\
\hline perillic acid & 223 & $(4.32 \pm 0.05) \times 10^{5}$ & 0.9999 & 0.04 & 0.02 \\
\hline 8-hydroxyoctanoic acid & 331 & $(2.33 \pm 0.07) \times 10^{5}$ & 0.9970 & 0.07 & 0.04 \\
\hline D-malic acid & 419 & $(1.2 \pm 0.3) \times 10^{5}$ & 0.9623 & 0.07 & 0.04 \\
\hline pinic acid & 171 & $(2.6 \pm 0.4) \times 10^{5}$ & 0.9887 & 0.3 & 0.2 \\
\hline
\end{tabular}

(*) Given for a sampling volume of $2 \mathrm{~m} 3$. a: 5 points from 80 to $1280 \mathrm{ng}$. b: 4 points from 160 to $1280 \mathrm{ng}$.

Table 6. Characteristic fragmentation of PFBHA and MTBSTFA derivatives in EI and CI modes.

\begin{tabular}{|c|c|c|c|c|c|}
\hline $\begin{array}{l}\text { PFBHA } \\
\text { derivatives } \\
\text { EI ions }\end{array}$ & $\begin{array}{l}\text { Fragments } \\
(m / z)\end{array}$ & $\begin{array}{l}\text { MTBSTFA } \\
\text { derivatives } \\
\text { EI ions }\end{array}$ & $\begin{array}{l}\text { Fragments } \\
(m / z)\end{array}$ & $\begin{array}{l}\text { CI } \\
\text { ions }\end{array}$ & $\begin{array}{l}\text { Fragments } \\
(\mathrm{m} / \mathrm{z})\end{array}$ \\
\hline $\begin{array}{l}181 \\
M-181 \\
M-197\end{array}$ & $\begin{array}{l}{\left[\mathrm{C}_{6} \mathrm{~F}_{5} \mathrm{CH}_{2}\right]^{+}} \\
{\left[\mathrm{M}-\mathrm{C}_{6} \mathrm{~F}_{5} \mathrm{CH}_{2}\right]^{+}} \\
{\left[\mathrm{M}-\mathrm{C}_{6} \mathrm{~F}_{5} \mathrm{CH}_{2} \mathrm{O}\right]^{+}}\end{array}$ & $\begin{array}{l}73 \\
75 \\
M-15 \\
M-57 \\
M-115 \\
M-131\end{array}$ & $\begin{array}{l}{\left[\mathrm{Si}\left(\mathrm{CH}_{3}\right)_{3}\right]^{+}} \\
{\left[\mathrm{HOSi}\left(\mathrm{CH}_{3}\right)_{2}\right]^{+}} \\
{\left[\mathrm{M}-\mathrm{CH}_{3}\right]^{+}} \\
{\left[\mathrm{M}-\mathrm{C}\left(\mathrm{CH}_{3}\right)_{3}\right]^{+}} \\
{\left[\mathrm{M}-\mathrm{Si}\left(\mathrm{CH}_{3}\right)_{2} \mathrm{C}\left(\mathrm{CH}_{3}\right)_{3}\right]^{+}} \\
{\left[\mathrm{M}-\mathrm{OSi}\left(\mathrm{CH}_{3}\right)_{2} \mathrm{C}\left(\mathrm{CH}_{3}\right)_{3}\right]^{+}}\end{array}$ & $\begin{array}{l}M+1 \\
M+29 \\
M+41\end{array}$ & $\begin{array}{l}{[\mathrm{M}+\mathrm{H}]^{+}} \\
{\left[\mathrm{M}+\mathrm{C}_{2} \mathrm{H}_{5}\right]^{+}} \\
{\left[\mathrm{M}+\mathrm{C}_{3} \mathrm{H}_{5}\right]^{+}}\end{array}$ \\
\hline
\end{tabular}

per filter and in concentration units for a sampling volume of $2 \mathrm{~m}^{3}$ (i.e. $16.71 \mathrm{~min}^{-1}$ for $2 \mathrm{~h}$ ). The linearity was not validated for two standard compounds, i.e. 4-oxoheptanedioic acid (keto-di-acid) and 3-carboxyhexanedioic acid (tri-acid), which have, besides high detection limits, close to $100 \mathrm{ng}$ per filter sample. Nevertheless, the analytical responses of these two compounds were linear, as previously tested, by on-Tenax TA derivatisation with MTBSTFA. Improvement of the developed particulate-phase MTBSTFA derivatisation protocol is consequently required to specifically quantify keto-di-acids and tri-acids. Detection limits for all other compounds range from 0.04 to $1.0 \mathrm{ng}$ per filter. These detection limits are significantly better than those obtained by Chiappini et al. (2006), which range from 1 to $7 \mathrm{ng}$ for an analogous series of acids, keto-acids and di-acids, using derivatisation with BSTFA during supercritical fluid extraction coupled to GC/MS analysis. The detection limits are more than satisfactory to measure carboxylic acids in atmospheric particles since their concentration levels are about a few tens of $\mathrm{ng} \mathrm{m}^{-3}$ as measured by Sun and Ariya (2006). 
Table 7. Tentative or positive identification for observed carbonyl compounds, organic acids and hydroxyls compounds from limonene ozonolysis 1 experiment. MW D.: molecular weight of the derivatised compound. MW non-D.: molecular weight of the non-derivatised compound. LOD: limit of detection. G: detected in the gas phase. P: detected in the particulate phase.

\begin{tabular}{|c|c|c|c|c|c|c|c|c|c|}
\hline \multirow[t]{2}{*}{$\begin{array}{l}\text { Compound } \\
\text { number }\end{array}$} & \multirow[t]{2}{*}{ Mass fragments } & \multicolumn{7}{|c|}{ Tentative assignment } & \multirow[t]{2}{*}{ Phase(s) } \\
\hline & & MW D. & \multicolumn{2}{|l|}{$\begin{array}{r}\text { Functional } \\
\text { groups }\end{array}$} & Name & Structure & \multicolumn{2}{|c|}{ Assignment } & \\
\hline \multicolumn{10}{|c|}{ Carbonyls compounds (PFBHA derivatives) } \\
\hline P1 & $\begin{array}{l}\text { EI: } 181(100), \quad M-181=112, \quad M=293 \\
\text { CI: } \quad M+1 \quad=294 \quad M+29=322, \\
M+41=334\end{array}$ & 293 & 1 & 98 & 5-hexene-2-one & & Nist EI list & $\begin{array}{l}\text { Unique to this } \\
\text { study }\end{array}$ & G-P \\
\hline P2 & $\begin{array}{l}\text { EI: } 42,95(100), \quad M-181=152, \quad 181, \\
M=333 \text { CI: } 95,181, M+1=334, \\
M+29=362, M+41=374\end{array}$ & 333 & 1 & 138 & keto-limonene & & $\begin{array}{l}\text { Proposed from } \\
\text { mass spectra }\end{array}$ & $\begin{array}{l}\text { Forester and } \\
\text { Wells (2009), Jaoui } \\
\text { et al. (2006) }\end{array}$ & G \\
\hline P3 & $\begin{array}{l}\text { EI: } \quad 181(100), \quad M-197=265, \quad M=462 \\
\text { CI: } \quad M+1=463, \quad M+29=491, \\
M+41=503\end{array}$ & 462 & 2 & 72 & methylglyoxal & o & $\begin{array}{l}\text { Proposed from } \\
\text { mass spectra }\end{array}$ & $\begin{array}{ll}\text { Forester } & \text { and } \\
\text { Wells (2009) }\end{array}$ & G-P \\
\hline $\mathrm{P} 4$ & $\begin{array}{l}\text { EI: } \quad 181(100), \quad M-197=279, \quad M=476 \\
\text { CI: } \quad M+1=477, \quad M+29=505, \\
M+41=517\end{array}$ & 476 & 2 & 86 & dimethylglyoxal & & Standard & $\begin{array}{l}\text { Unique to this } \\
\text { study }\end{array}$ & G-P \\
\hline P5 & $\begin{array}{l}\text { EI: } 181(100), 279, \quad M-197=293, M- \\
181=309, \quad M=490 \quad \text { CI: } M+1=491, \\
M+29=519, M+41=531\end{array}$ & 490 & 2 & 100 & 4-oxopentanal & & Standard & $\begin{array}{l}\text { Forester and } \\
\text { Wells (2009) }\end{array}$ & G-P \\
\hline P6 & $\begin{array}{l}\text { EI: } 181(100), 320,558, M-197=361, \\
M-181=377, \quad \text { CI: } \quad M+1=559, \\
M+29=587, M+41=599\end{array}$ & 558 & 2 & 168 & limononaldehyde & & $\begin{array}{l}\text { Proposed from } \\
\text { mass spectra }\end{array}$ & $\begin{array}{l}\text { Leungsakul et } \\
\text { al. (2005b), Jaoui } \\
\text { et al. (2006) }\end{array}$ & G-P \\
\hline P7 & $\begin{array}{l}\text { EI: } 181(100), \quad 305, \quad M-197=516, \\
M=713 \text { CI: }<\text { LOD }\end{array}$ & 713 & 3 & 128 & dioxohexanal & & $\begin{array}{l}\text { Proposed from } \\
\text { mass spectra }\end{array}$ & $\begin{array}{l}\text { Unique to this } \\
\text { study }\end{array}$ & $\mathrm{P}$ \\
\hline P8 & $\begin{array}{l}\text { EI: } 138,181(100), 319 \mathrm{M}-197=530 \text {, } \\
M=727 \text { CI: } M+1=728\end{array}$ & 727 & 3 & 142 & 3,6-dioxoheptanal & & $\begin{array}{l}\text { Proposed from } \\
\text { mass spectra }\end{array}$ & $\begin{array}{l}\text { Leungsakul et } \\
\text { al. (2005b) }\end{array}$ & $\mathrm{P}$ \\
\hline P9 & $\begin{array}{l}\text { EI: } 94,181(100), 347, M-197=558, \\
\text { M-181=574, M=755 CI: }<\text { LOD }\end{array}$ & 755 & 3 & 170 & keto-limononaldehyde & & $\begin{array}{l}\text { Proposed from } \\
\text { mass spectra }\end{array}$ & $\begin{array}{l}\text { Leungsakul et } \\
\text { al. (2005b), Jaoui } \\
\text { et al. (2006) }\end{array}$ & $\mathrm{P}$ \\
\hline \multicolumn{10}{|c|}{ Hydroxyl and carboxyl compounds (MTBSTFA derivatives) } \\
\hline M1 & $\begin{array}{l}\text { EI: } 75,99, \quad 145, \quad M-15=215, \quad M- \\
57=173(100) \text { CI: }<\text { LOD }\end{array}$ & 230 & 1 & 116 & levulinic acid & & Standard & Jaoui et al. (2006) & G \\
\hline M2 & $\begin{array}{l}\text { EI: } 73,116,147, \text { M-57=289(100), M- } \\
15=331 \text { CI: }<\text { LOD }\end{array}$ & 346 & 2 & 118 & succinic acid & & Standard & Jaoui et al. (2006) & G-P \\
\hline M3 & $\begin{array}{l}\text { EI: } 73(100), 123,147, M-57=303, M- \\
15=345 \text { CI: } 115,173,229, M-57=303, \\
M-15=345, M+1=361, M+29=389, \\
M+41=401\end{array}$ & 360 & 2 & 132 & 2-methylbutanedioic acid & & $\begin{array}{l}\text { Nist EI list match } \\
75 \%\end{array}$ & $\begin{array}{l}\text { Unique to this } \\
\text { study }\end{array}$ & G \\
\hline M4 & $\begin{array}{l}\text { EI: } 73,129,147 \mathrm{M}-57=303(100), \mathrm{M}- \\
15=345 \mathrm{CI}: 115,165,229, \mathrm{M}-57=303, \\
M-15=345, M+1=361, M+29=389 \\
M+41=401\end{array}$ & 360 & 2 & 132 & pentanedioic acid & & $\begin{array}{l}\text { Proposed from } \\
\text { mass spectra }\end{array}$ & Jaoui et al. (2006) & G-P \\
\hline M5 & $\begin{array}{l}\text { EI: } 73,133,147,157(100), 185,215, \\
289, M-57=317, M-15=359 \text { CI: } 215, \\
M-57=317, M-15=359, M+1=375 \\
M+29=403, M+41=415\end{array}$ & 374 & 2 & 146 & $\alpha-$ ketoglutaric acid & & Standard & $\begin{array}{l}\text { Unique to this } \\
\text { study }\end{array}$ & $\mathrm{P}$ \\
\hline M6 & $\begin{array}{l}\text { EI: } 73, \quad 111, \quad 141 \quad M-57=317(100) \\
M-15=359 \quad \text { CI: } 257, \quad M-57=317 \\
M-15=359, \quad M+1=375, M+29=403 \\
M+41=415\end{array}$ & 374 & 2 & 146 & hexanedioic acid & & $\begin{array}{l}\text { Nist EI list match } \\
92 \%\end{array}$ & Jaoui et al. (2006) & G-P \\
\hline
\end{tabular}


Table 7. Continued.

\begin{tabular}{|c|c|c|c|c|c|c|c|c|c|}
\hline \multirow[t]{3}{*}{$\begin{array}{l}\text { Compound } \\
\text { number }\end{array}$} & \multirow[t]{3}{*}{ Mass fragments } & \multicolumn{7}{|c|}{ Tentative assignment } & \multirow[t]{3}{*}{ Phase(s) } \\
\hline & & & $\begin{array}{r}\text { Functional } \\
\text { groups }\end{array}$ & & & \multirow{2}{*}{\multicolumn{3}{|c|}{ Assignment }} & \\
\hline & & MW D. & number & MW non-D. & Name & & & & \\
\hline M7 & $\begin{array}{l}\text { EI: } 73,75,111,185,317, M-57= \\
345(100), M-15=387 \text { CI: }<\text { LOD }\end{array}$ & 402 & 2 & 174 & ketonorlimonic acid & & $\begin{array}{l}\text { Proposed from } \\
\text { mass spectra }\end{array}$ & Jaoui et al. (2006) & $P$ \\
\hline M8 & $\begin{array}{l}\text { EI: } 73,75,111,185,317, \text { M-57= } \\
345(100), \text { M-15=387 CI: }<\text { LOD }\end{array}$ & 402 & 2 & 174 & 4-oxoheptanedioic acid & & Standard & $\begin{array}{l}\text { Unique to this } \\
\text { study }\end{array}$ & $\mathrm{P}$ \\
\hline M9 & $\begin{array}{l}\text { EI: } 73,75, \quad 147, \quad M-115=299, \quad M- \\
57=357(100), M-15=399, \quad M=414 \\
\text { CI: }<\text { LOD }\end{array}$ & 414 & 2 & 186 & limonic acid & & $\begin{array}{l}\text { Proposed from } \\
\text { mass spectra }\end{array}$ & $\begin{array}{l}\text { Jaoui et } \\
\text { al. (2006), } \\
\text { Leungsakul et } \\
\text { al. (2005b) }\end{array}$ & G-P \\
\hline M10 & $\begin{array}{l}\text { EI: } 73,75,147,185,331, \text { M-57= } \\
\text { 359(100), M-15=401 CI: }<\text { LOD }\end{array}$ & 416 & 2 & 188 & ketolimonic acid & & $\begin{array}{l}\text { Proposed from } \\
\text { mass spectra }\end{array}$ & Jaoui et al. (2006) & $\mathrm{P}$ \\
\hline M11 & $\begin{array}{l}\text { EI: } 73(100), 75,99,147,225,255, M- \\
57=385, \mathrm{M}-15=427 \text { CI: }<\text { LOD }\end{array}$ & 442 & 2 & 214 & $\begin{array}{l}\text { 3-acetyl-4-methylhept- } \\
\text { 3-enedioic acid }\end{array}$ & & $\begin{array}{l}\text { Proposed from } \\
\text { mass spectra }\end{array}$ & $\begin{array}{l}\text { Unique to this } \\
\text { study }\end{array}$ & $\mathrm{P}$ \\
\hline M12 & $\begin{array}{l}\text { EI: } 73(100), \quad 115, \quad 147, \quad 287, \quad M- \\
57=419, \text { M-15=461 CI: <LOD }\end{array}$ & 476 & 3 & 134 & $\begin{array}{l}\text { 2-hydroxybutanedioic } \\
\text { acid (malic acid) }\end{array}$ & & Standard & $\begin{array}{l}\text { Unique to this } \\
\text { study }\end{array}$ & $\mathrm{P}$ \\
\hline M13 & $\begin{array}{l}\text { EI: } 73(100), 133,147,171,245 \text {, } \\
\text { 273, 331, M-57=433, M-15=475 CI: } \\
\text { <LOD }\end{array}$ & 490 & 3 & 148 & $\begin{array}{l}\text { 2-hydroxypentanedioic } \\
\text { acid }\end{array}$ & & $\begin{array}{l}\text { Nist EI list match } \\
98 \%\end{array}$ & $\begin{array}{l}\text { Unique to this } \\
\text { study }\end{array}$ & $\mathrm{P}$ \\
\hline M14 & $\begin{array}{l}\text { EI: } 73(100), 115,133,147,171,273 \text {, } \\
\text { M- } 57=447, M-15=489 \text { CI: }<\text { LOD }\end{array}$ & 504 & 3 & 162 & $\begin{array}{l}\text { 3-hydroxyhexanedioic } \\
\text { acid }\end{array}$ & & $\begin{array}{l}\text { Proposed from } \\
\text { mass spectra }\end{array}$ & $\begin{array}{l}\text { Unique to this } \\
\text { study }\end{array}$ & $\mathrm{P}$ \\
\hline M15 & $\begin{array}{l}\text { EI: } 73,147,301, M-131=387, \quad M- \\
57=461(100), M-15=503 \text { CI: <LOD }\end{array}$ & 518 & 3 & 176 & $\begin{array}{l}\text { 3-carboxypentanedioic } \\
\text { acid }\end{array}$ & & $\begin{array}{l}\text { Proposed from } \\
\text { mass spectra }\end{array}$ & $\begin{array}{l}\text { Unique to this } \\
\text { study }\end{array}$ & $\mathrm{P}$ \\
\hline M16 & $\begin{array}{l}\text { EI: } 73, \quad 147,269,301,385, \quad \text { M- } \\
\text { 131=401, M-57=475(100), M- } \\
15=517 \text { CI: }<\text { LOD }\end{array}$ & 532 & 3 & 190 & $\begin{array}{l}\text { 3-carboxyhexanedioic } \\
\text { acid }\end{array}$ & & Standard & $\begin{array}{l}\text { Unique to this } \\
\text { study }\end{array}$ & $\mathrm{P}$ \\
\hline
\end{tabular}

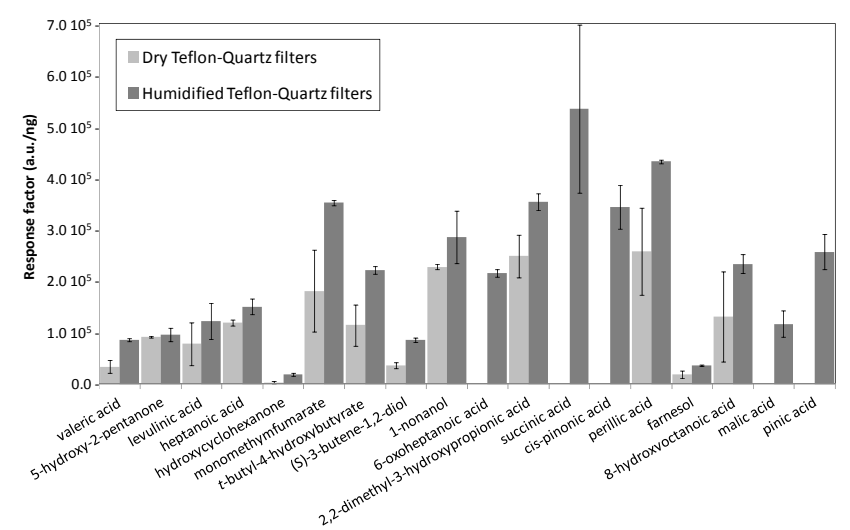

Fig. 12. Humidity influence on on-Teflon-quartz filters organic acids and hydroxyl compounds MTBSTFA-derivatisation. Comparison is based on response factors evaluated from 5 point calibration curves ( 5 to $320 \mathrm{ng}$ ). "Response factor" refers to FID chromatogram surface peak area per ng of compound, in area units. Error bars represent \pm two standard errors given for a $95 \%$ confidence level.

\section{Method application to limonene ozonolysis in a simulated atmosphere}

Limonene is a significant contributor to monoterpene emissions, which accounts for around $11 \%$ of global VOC emissions (Guenther et al., 1995). Moreover, with two double bonds, it is more reactive and has a higher SOA yield (around twice, Griffin et al., 1999) compared to mono-unsaturated monoterpenes, such as $\alpha$ - and $\beta$-pinene, which are emitted in large amounts at a global scale. Limonene is consequently supposed to be a significant contributor to SOA. Furthermore, limonene is also widely present in indoor environments as it is largely employed in household cleaning products, air fresheners or essential oils (Singer et al., 2006). Limonene oxidation in indoor environments, especially through ozonolysis, has been demonstrated in many studies during the last years, pointing out strong airway irritants and ultrafine particle formation (Clausen et al., 2001; Sarwar and Corsi, 2007; Langer et al., 2008; Coleman et al., 2008; Forester and Wells, 2009; Jardine et al., 2011).

Therefore, limonene ozonolysis was chosen as a relevant system to assess the potential of the developed method to explore the chemical composition of oxygenated secondary 


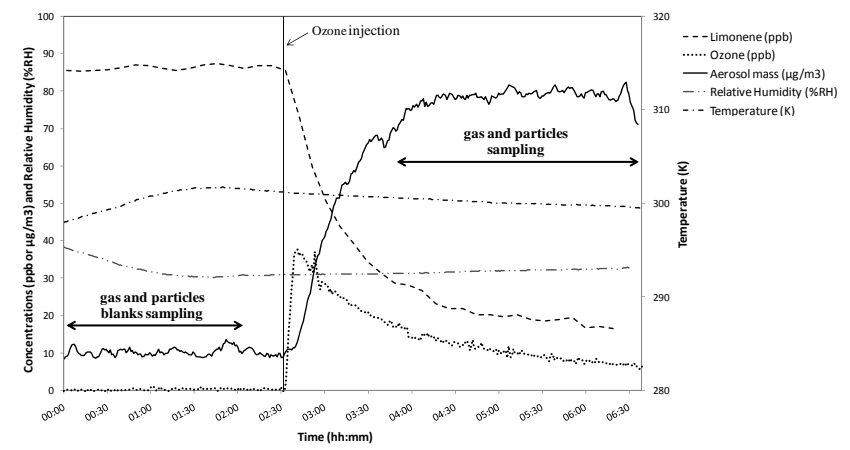

Fig. 13. Evolution of limonene ozonolysis experiment parameters.

organic matter simultaneously in gaseous and particulate phases. Moreover, this chemical system is sufficiently well characterised, allowing us to compare our results to the literature for method validation purposes (e.g. Leungsakul et al., 2005a, b; Jaoui et al., 2006; Walser et al., 2007; Forester and Wells, 2009).

\subsection{Experimental protocol}

A limonene ozonolysis experiment was conducted in the EUPHORE simulation chamber (cf. Sect. 2.3.3) to simulate real indoor or outdoor atmospheric conditions. Limonene was first injected into the chamber at an initial concentration level of $100 \mathrm{ppb}$. Non-acidified sulphate ammonium seeds were introduced by nebulisation of a $0.02 \mathrm{M}$ solution at a concentration of $12.5 \mu \mathrm{g} \mathrm{m}^{-3}$. Water was then introduced until an initial relative humidity of $50 \%$ was reached. Ozone was finally injected during $5 \mathrm{~min} 16 \mathrm{~s}$, corresponding to an initial concentration of $105 \mathrm{ppb}$ (see Sect. 2.3.3). The average temperature during the experiment was $300 \pm 1 \mathrm{~K}$. No hydroxyl radical scavenger was introduced as this would stray the experiment from realistic indoor conditions (Docherty and Ziemann, 2003; Jonsson et al., 2008). Main parameter variations as monitored during the course of the experiment are given in Fig. 13.

In order to evaluate the fraction of the oxidative chemistry initiated by hydroxyl radicals on limonene - originating from Criegee intermediate decomposition after ozone addition onto double bonds - a simulation was run using the Master Chemical Mechanism, MCM v3.2 (Jenkin et al., 1997; Saunders et al., 2003). Initialising the MCM with our experimental conditions, it was found that around twothirds of the initial limonene amount reacts with ozone, while one-third is expected to react with hydroxyl radicals. As a result, both ozonolysis and photo-oxidation products of limonene are likely to be detected and are thus consequently specifically investigated.

Blanks were sampled just before ozone introduction during $120 \mathrm{~min}$. Gas-phase blanks were sampled on one PFBHA- and one MTBSTFA-coated Tenax TA tubes at a flow rate of $100 \mathrm{ml} \mathrm{min}^{-1}$ downstream from a Teflon fil- ter (Zefluor, $47 \mathrm{~mm}$, Pall Life Sciences). Particulate-phase blanks were sampled in parallel on one quartz filter and one Teflon-quartz filter at a flow rate of $16.71 \mathrm{~min}^{-1}$. Sampling was performed during $160 \mathrm{~min}$ after ozone introduction and system stabilisation (aerosol maximum mass reached within one hour). The gas phase was sampled onto three PFBHAand three MTBSTFA-coated Tenax TA tubes at a flow rate of $100 \mathrm{ml} \mathrm{min}^{-1}$ downstream from a Teflon filter. For each derivatisation reagent, one tube was equipped with a back-up tube (see Sect. 3.2.4) which was coated in the same way to observe possible breakthrough of the sample tubes. The particulate phase was sampled onto one Teflon-quartz and two quartz filters at a flow rate of $16.71 \mathrm{~min}^{-1}$. No VOC denuder was used in this method testing experiment. It is important to note that no specific set-up was used to minimise sampling artifact for these experiments, as the main objective of the experiments here was the application of the methodology presented and characterised in the previous section.

All samples were analysed by TD/GC/MS, in both EI and CI modes, as previously described (cf. Sect. 2.2.).

\subsection{Results}

\subsubsection{Aerosol mass yield}

The secondary aerosol growth curve for the limonene ozonolysis experiment is given in Fig. 14. The aerosol mass yield corresponds to the time-dependant aerosol mass yield $\mathrm{Y}$ calculated from TEOM measurements and is defined as:

$Y=\frac{\Delta M_{0}}{\Delta \mathrm{HC}}$

where $\Delta M_{0}$ is the aerosol mass loading $\left(\mu \mathrm{g} \mathrm{m}^{3}\right)$ and $\Delta \mathrm{HC}$ is the total reacted limonene $\left(\mu \mathrm{g} \mathrm{m}^{3}\right)$, both corrected for dilution and wall losses. The final aerosol mass yield was around $20 \%$. Higher values are usually observed in the same experimental conditions ( $\sim 50 \%$ by Jaoui et al., 2006, Northcross and Jang, 2007, Sun et al., 2011, 65\% by Saathoff et al., 2009). The lower value measured here can be explained by the elevated temperature of $300 \mathrm{~K}$ achieved in the chamber during our experiment, as demonstrated by Saathoff et al. (2009) who examined the influence of temperature on SOA yields from limonene ozonolysis.

\subsubsection{Product detection and identification}

Compound detection and identification were based on characteristic fragmentation patterns of PFBHA and MTBSTFA derivatives (cf. Table 6) in EI and CI modes. The mass spectra of derivatised compounds and their retention time were compared to available standard data. Compounds were positively identified in the case where standards are available. Otherwise, a tentative assignment is proposed based on the comparison of the fragmentation pattern and the retention time with surrogate standards. Compounds detected 
Table 8. Quantification of observed carbonyl compounds, organic acids and hydroxyl compounds. LOD: limit of detection. 1 nd: not detected.

\begin{tabular}{|c|c|c|c|c|}
\hline $\begin{array}{l}\text { Compound } \\
\text { number }\end{array}$ & Compound & $\begin{array}{l}\text { Calibration } \\
\text { standard }\end{array}$ & $\begin{array}{r}\text { Gas phase } \\
\text { concentration }\left(\mathrm{ng} \mathrm{m}^{-3}\right)\end{array}$ & $\begin{array}{r}\text { Particulate } \\
\text { phase concentration } \\
\left(\mathrm{ng} \mathrm{m}^{-3}\right)\end{array}$ \\
\hline \multicolumn{5}{|c|}{ Carbonyl compounds (PFBHA derivatives) } \\
\hline $\mathrm{P} 1$ & 5-hexene-2-one & 3-pentene-2-one & $166 \pm 4$ & $10 \pm 4$ \\
\hline $\mathrm{P} 2$ & keto-limonene & dihydrocarvone & $1830 \pm 40$ & $<$ LOD \\
\hline P3 & methylglyoxal & methylglyoxal & $2500 \pm 600$ & $70 \pm 30$ \\
\hline P4 & dimethylglyoxal & dimethylglyoxal & $2500 \pm 200$ & $6.3 \pm 0.9$ \\
\hline P5 & 4-oxopentanal & 4-oxopentanal & $1760 \pm 60$ & $51 \pm 3$ \\
\hline P6 & limononaldehyde & 4-oxopentanal & $7800 \pm 300$ & $640 \pm 30$ \\
\hline \multicolumn{5}{|c|}{ Hydroxyl compounds and organic acids (MTBSTFA derivatives) } \\
\hline M1 & levulinic acid & levulinic acid & $990 \pm 60$ & nd \\
\hline M2 & succinic acid & succinic acid & $18 \pm 1$ & $7 \pm 3$ \\
\hline M3 & 2-methylbutanedioic acid & succinic acid & $4.8 \pm 0.3$ & nd \\
\hline M4 & pentanedioic acid & succinic acid & $13.9 \pm 0.9$ & $4 \pm 1$ \\
\hline M6 & hexanedioic acid & succinic acid & $29 \pm 2$ & $12 \pm 5$ \\
\hline M9 & limonic acid & pinic acid & $2.9 \pm 0.3$ & $70 \pm 10$ \\
\hline M12 & malic acid & malic acid & nd & $12 \pm 3$ \\
\hline M13 & 2-hydroxypentanedioic acid & malic acid & nd & $6 \pm 2$ \\
\hline M14 & 3-hydroxyhexanedioic acid & malic acid & nd & $17 \pm 5$ \\
\hline
\end{tabular}

Table 9. Experimental partitioning coefficient $K_{i}\left(\mathrm{~m}^{3} \mu \mathrm{g}^{-1}\right)$ compared with $K_{i}$ values $\left(\mathrm{m}^{3} \mu \mathrm{g}^{-1}\right)$ estimated from theoretical saturation vapour pressures $\left(P_{\mathrm{L}, i}^{\mathrm{O}}\right)$ calculated from 3 group contribution methods at $298 \mathrm{~K} . K_{i}$ calculation assumes a temperature of $300 \mathrm{~K}$, a mean $\mathrm{MW}_{\mathrm{om}}$ of $142 \mathrm{~g} \mathrm{~mol}^{-1}$ and an activity coefficient $\gamma_{i}$ of 1.27. MY: Myrdal and Yalkowsky, 1997. NAN: Nannoolal et al., 2008. SIM: Pankow and Asher, 2008.

\begin{tabular}{llcccc}
\hline \multirow{2}{*}{$\begin{array}{l}\text { Compound } \\
\text { number }\end{array}$} & Compound & Experimental $K_{i}$ & \multicolumn{3}{c}{ Estimated $K_{i}$ values } \\
\cline { 3 - 5 } & & & MY & NAN & SIM \\
\hline \multicolumn{2}{l}{ Carbonyl compounds (PFBHA derivatives) } & & & \\
\hline P1 & 5-hexene-2-one & $1.3 \times 10^{-3} \pm 67 \%$ & $4.54 \times 10^{-9}$ & $9.14 \times 10^{-9}$ & $7.26 \times 10^{-9}$ \\
P3 & methylglyoxal & $1.3 \times 10^{-3} \pm 84 \%$ & $2.14 \times 10^{-9}$ & $8.77 \times 10^{-10}$ & $6.49 \times 10^{-9}$ \\
P4 & dimethylglyoxal & $7.4 \times 10^{-5} \pm 47 \%$ & $7.11 \times 10^{-9}$ & $3.48 \times 10^{-9}$ & $7.00 \times 10^{-9}$ \\
P5 & 4-oxopentanal & $6.5 \times 10^{-4} \pm 34 \%$ & $1.67 \times 10^{-8}$ & $1.45 \times 10^{-8}$ & $4.53 \times 10^{-8}$ \\
P6 & limononaldehyde & $1.9 \times 10^{-3} \pm 34 \%$ & $4.54 \times 10^{-6}$ & $1.35 \times 10^{-6}$ & $7.50 \times 10^{-6}$ \\
\hline Hydroxyl compounds and organic acids $(\mathrm{MTBSTFA} \mathrm{derivatives)}$ & & \\
\hline M2 & succinic acid & $3.2 \times 10^{-2} \pm 73 \%$ & $5.16 \times 10^{-4}$ & $3.00 \times 10^{-4}$ & $1.04 \times 10^{-3}$ \\
M4 & pentanedioic acid & $7.8 \times 10^{-3} \pm 73 \%$ & $1.90 \times 10^{-3}$ & $1.08 \times 10^{-3}$ & $2.76 \times 10^{-3}$ \\
M6 & hexanedioic acid & $6.9 \times 10^{-3} \pm 73 \%$ & $6.49 \times 10^{-3}$ & $3.38 \times 10^{-3}$ & $6.50 \times 10^{-3}$ \\
M9 & limonic acid & $5.1 \times 10^{-1} \pm 50 \%$ & $2.56 \times 10^{-1}$ & $2.51 \times 10^{-2}$ & $1.54 \times 10^{-1}$ \\
\hline
\end{tabular}

in chamber blanks in the same order of magnitude than in samples were removed from the product list.

Around 30 compounds could be detected in the gas phase as PFBHA or MTBSTFA derivative products (20 PFBHA derivatives and 10 MTBSTFA derivatives) and around 65 in the particulate phases (30 PFBHA derivatives and 35 MTBSTFA derivatives). These products ranged from $C_{3}$ - to $C_{10^{-}}$ compounds and from mono- to tri-functionalised species. Compounds detected in the gas phase ranged from $\mathrm{C}_{3}$ monocarbonyl, $\mathrm{C}_{5}$ mono-hydroxyl or $\mathrm{C}_{6}$ mono-acid to $\mathrm{C}_{10}$ dicarbonyl and $\mathrm{C}_{8}$ di-hydroxyl or di-acids. In the particulate phase, tri-functionalised compounds were observed in the $\mathrm{C}_{8}-\mathrm{C}_{10}$ range. 


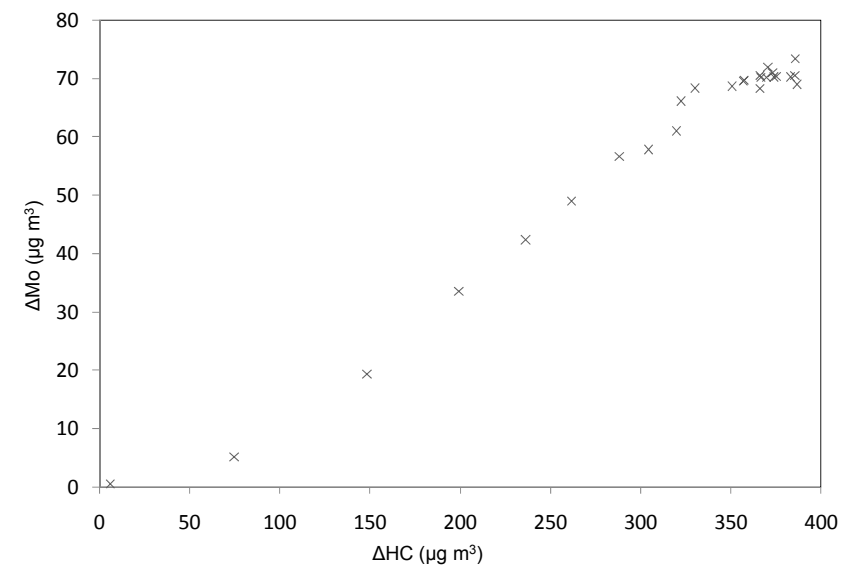

Fig. 14. Limonene ozonolysis experiment growth curve. Data corrected by dilution and wall losses.

Among all these detected products, 25 have been positively (based on standard mass spectra comparison) or tentatively identified (based on surrogate standard and/or mass spectra). An overview of the limonene oxidation products detected and tentatively or positively identified in both gas and particulate phases is presented in Table 7. Thirteen products previously identified from limonene oxidation experiments (Leungsakul et al., 2005a; Jaoui et al., 2006; Forester and Wells, 2009) or expected from theoretical oxidation schemes (Leungsakul et al., 2005b) were observed (P2, P3, P5, P6, P8, P9, M1, M2, M4, M6, M7, M9 and M10).

In addition to these species, twelve other products were, to the best of our knowledge, detected for the first time (P1, P4, P7, M3, M5, M8, M11, M12, M13, M14, M15, and M16).

This provides certainly the most comprehensive list of detected compounds in a single experiment for limonene ozonolysis in both gaseous and particulate phases.

This new information shows the potential of the method to explore the chemical composition of the secondary organic matter in a relevant range of semi-volatile compounds, and, hence, opens the way to new chemical scheme building for the production of semi-volatile organic species in the limonene ozonolysis system. An example of chromatograms is given for the analysis of carbonyl compounds in both phases (Fig. 15).

Re-collection (see Sect. 2.2.1) was used here to perform GC/MS analysis in both the EI and the CI modes successively for all gas- and particulate-phase samples, as this procedure was a convenient way to obtain complementary data for compound identification. Nevertheless, it must be indicated here that this approach is affected by an elevated detection limit obtained in CI mode for re-collected samples, especially for MTBSTFA-derivatised samples. The analysis of the re-collected samples was not validated for quantification as the re-collection efficiency was not evaluated. Furthermore, further experiments revealed that re-collected
MTBSTFA samples have to be analysed as soon as possible after first injection. Unfortunately, this was not possible in this study. Other attempts showed that a $24 \mathrm{~h}$ delay seems to significantly improve detection limits compared to the presented results for re-collected sample, analysed in the CI mode within 7 days.

\subsubsection{Quantification and estimation of partitioning coefficients}

Among the 30 compounds detected in the gas phase and the 65 compounds detected in the particulate phase with the developed parallel sampling and analysis method, only those for which a relevant standard calibration in the gas and/or particulate phases (cf. Tables 1, 3, 4 and 5) could be obtained were quantified. This led to the quantification of 18 detected compounds, which are given in Table 8. Values were corrected from chamber blanks. The mentioned uncertainties correspond to the statistical uncertainties (Student's t-test) previously determined for calibration curves. The total quantified products represent around $16 \%$ of the carbon mass of the reacted limonene. The remaining nonquantified mass can be divided in three main groups: (1) nonidentified compounds that were detected here but not quantified, (2) non-derivatisable species, and (3) high molecular weight compounds such as oligomers.

For compounds quantified in both the gas and particulate phases, an experimental partitioning coefficient was calculated (Table 9). However, as the whole mass of a given compound present in the chamber participates to the partitioning of this compound, quantifications values used for partitioning coefficients calculation were not corrected from chamber blank values but only from laboratory blank values. A total aerosol concentration of $45 \pm 12 \mu \mathrm{g} \mathrm{m}^{-3}$ was considered, which corresponds to the average real aerosol concentration during sampling, not corrected for aerosol losses in the chamber. Uncertainties were calculated on the basis of gas-phase, particulate-phase and aerosol mass quantification uncertainties (calibration curves and TEOM uncertainty). As no denuder was used for upstream quartz and Teflon-quartz sample filters to prevent positive artifacts on the particulate-phase compounds quantification, the determined experimental partitioning coefficients represent the best estimates under the conditions applied. In order to illustrate the usefulness of determining experimental partitioning coefficients and highlight the relevance of the present method development, the determined experimental partitioning coefficients were compared to values calculated from theoretical vapour pressure data estimated for three group contribution methods (Myrdal and Yalkowsky, 1997 - MY; Nannoolal et al., 2008 - NAN; Pankow and Asher, 2008 - SIM). The following parameters were used for these calculations: an experimental temperature of $300 \mathrm{~K}$, an average molecular weight in the particulate phase $\left(\mathrm{MW}_{\mathrm{om}}\right)$ of $142 \mathrm{~g} \mathrm{~mol}^{-1}$ and an activity coefficient $\left(\gamma_{i}\right)$ of 1.27 . These two last values 

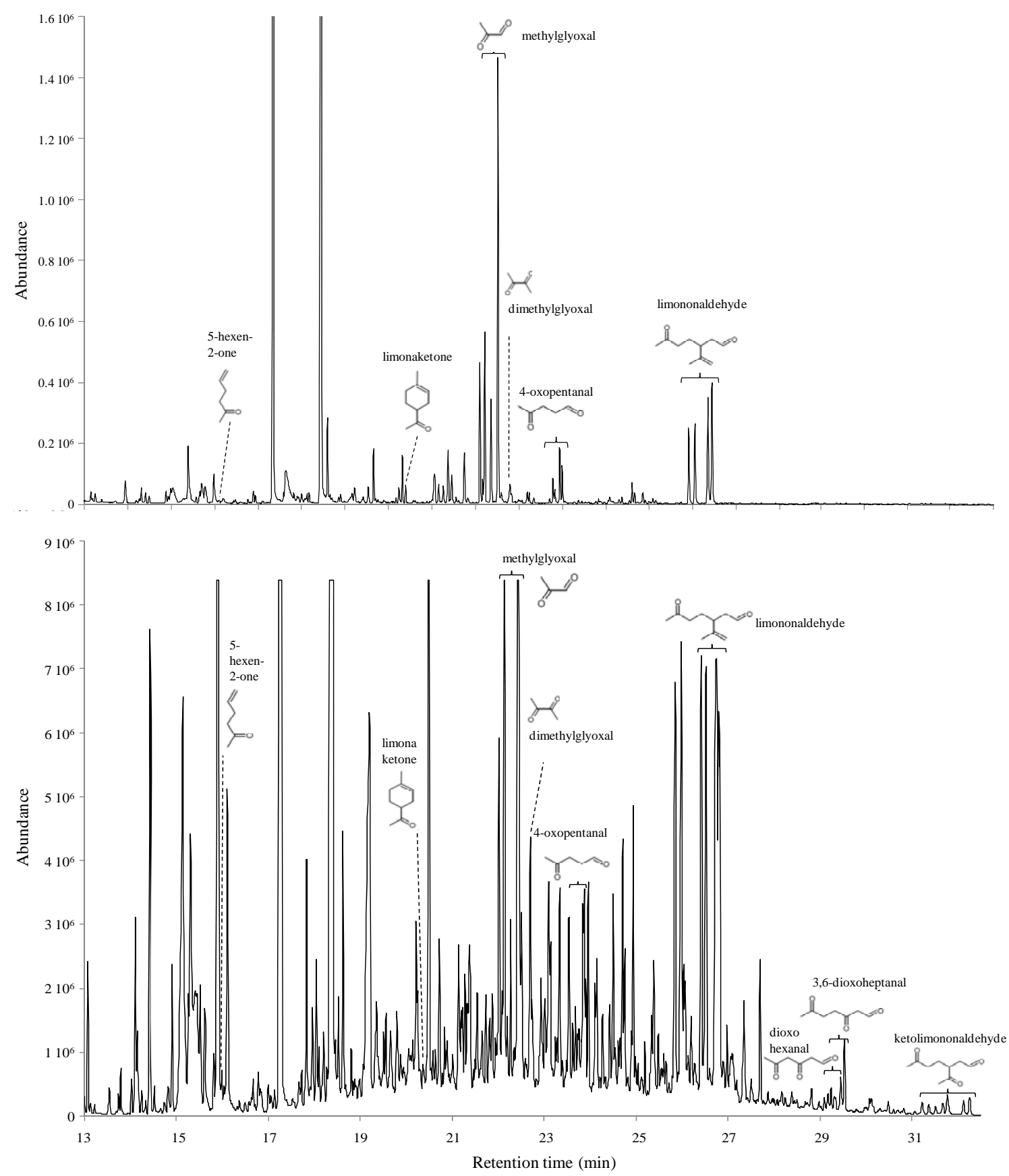

Fig. 15. Gas chromatograms of limonene ozonolysis products derivatised by PFBHA, EI selected ion $\mathrm{m} / z 181 \mathrm{chromatogram}$. Top chromatogram: gas phase. Bottom chromatogram: particulate phase.

are taken from simulation results reported by Leungsakul et al. (2005a). Besides, when available, experimental partitioning coefficients were also compared with other experimental values. Limononaldehyde (P6) was the most abundant product in the gas phase, as observed by Leungsakul et al. (2005a) for limonene ozonolysis experiments. However, contrary to this previous study, limononaldehyde was also the most abundant product in the particulate phase instead of keto-limononaldehyde. The experimental partitioning coefficient for limononaldehyde obtained in the present study is $3.5 \times 10^{-3} \mathrm{~m}^{3} \mu \mathrm{g}^{-1}$, a value which is three orders of magnitude higher than the estimated one by calculation and two orders of magnitude higher than the limononaldehyde experimental partitioning coefficients estimated by Leungsakul et al. (2005a) (around $6 \times 10^{-5} \mathrm{~m}^{3} \mu^{-1}$ ). 
The second most abundant products in the gas phase were methylglyoxal and dimethylglyoxal, methylglyoxal being also the second most abundant compound in the particulate phase. The experimental partitioning coefficient for methylglyoxal is also three orders of magnitude higher than estimated coefficients. However, it is similar to experimental values determined by Ortiz et al. (2010) during field $\left(3.4 \times 10^{-2} \mathrm{~m}^{3} \mu \mathrm{g}^{-1}\right)$ and toluene oxidation smog chamber $\left(1 \times 10^{-4} \mathrm{~m}^{3} \mu \mathrm{g}^{-1}\right)$ experiments. If this direct comparison can be affected by different aerosol properties and different sampling conditions and analytical techniques employed, our experimental value for the methylglyoxal partitioning coefficient can be considered as another clue suggesting that the eventually polymerised methylglyoxal concentration in the particulate phase, under atmospherically relevant conditions, could be higher than expected from semi-empirical group contribution methods.

Another important product detected in both gas and particulate phases was 4-oxopentanal (P5). This compound was previously detected as a limonene oxidation product only by Forester and Wells (2009). It was also observed at high levels in a forestal atmosphere, $180-1570 \mathrm{ng} \mathrm{m}^{3}$ in the gas phase and $25-207 \mathrm{ng} \mathrm{m}^{3}$ in the particulate phase (Matsunaga et al., 2004), indicating that 4-oxopentanal could be an important SOA contributor. However, its major source is assumed by these authors to be the oxidation of 6-methyl-5-heptene-2one (6-MHO), which originates from squalene oxidation). However, 6-MHO was not observed in the present study, suggesting another pathway for 4-oxopentanal formation, which will not be discussed here.

Experimental partitioning coefficient estimation for 4oxopentanal provides a value five orders of magnitude higher than estimation calculation.

Dioxohexanal (P7), 3,6-dioxoheptanal (P8) and ketolimononaldehyde (P9) were only quantified in the particulate phase, although their estimated partitioning coefficients predict a gas-phase concentration higher than $100000 \mu \mathrm{g} \mathrm{m}^{-3}$. More realistically, Leungsakul et al. (2005a) provide experimental partitioning coefficients of keto-limononaldehyde in the range of $1.41-1.76 \times 10^{-3} \mathrm{~m}^{3} \mu \mathrm{g}^{-1}$. From these values and the keto-limononaldehyde particulate phase concentration estimated in the present study, a gas-phase concentration of around $1400 \mathrm{ng} \mathrm{m}^{-3}$ could be expected, which is still largely above detection limits achieved for di-carbonyls compounds in the gas phase. From this observation, three hypotheses could be advanced. Firstly, tri-carbonyl compounds may not exist significantly in the gas phase under the experimental conditions of this work, and the ketolimononaldehyde gas-phase concentration quantified by Leungsakul and co-workers was either mainly a positive artifact due to volatilisation from the particulate phase or linked to different experimental conditions. Secondly, these compounds are more prone to a negative artifact upon quantification in the gas phase than di-carbonyl compounds. Owing to adsorption onto the Teflon filter placed upstream from the adsorbent tubes, this negative artifact is increasing as expected when decreasing compound volatility (Volckens and Leith, 2003). Thirdly, tri-carbonyl compounds may not be detectable when sampled onto gas collection Tenax TA tubes, owing to either derivatisation which may not be complete or to a limited desorption. Further experiments based on tricarbonyl standards are required to support or invalidate this last hypothesis.

Levulinic acid (M1) was the most important acid observed in the gas phase. $\mathrm{Li}$ and $\mathrm{Yu}$ (2005) proposed that levulinic acid is an oxidation product of 4-oxopentanal. Limonic acid (M9) was the major acid that could be precisely quantified in the particulate phase with a concentration of $70 \pm 10 \mathrm{ng} \mathrm{m}^{-3}$. A keto-diacid (M10: ketolimonic acid) and two tri-dicarboxylic acids (M15 and M16) were also identified in the particulate phase. However, since their standard or surrogate standards calibration curves were not linear, their concentrations were estimated on the basis of pinic acid for M10 $\left(160 \mu \mathrm{g} \mathrm{m}^{-3}\right)$ and malic acid for M15 and M16 $\left(100 \mu \mathrm{g} \mathrm{m}^{-3}\right.$ and $\left.80 \mu \mathrm{g} \mathrm{m}^{-3}\right)$. The experimental partitioning coefficient of limonic acid was of the same order of magnitude than estimation calculation from MY and SIM. However, it was an order of magnitude higher than NAN estimation calculation and experimental values provided by $\mathrm{Yu}$ et al. (1999) for other biogenic di-acids: pinic acid, caric acid and sabinic acid, $2.8-3.5 \times 10^{-2} \mu \mathrm{g} \mathrm{m}^{-3}, 3.3 \times 10^{-2} \mu \mathrm{g} \mathrm{m}^{-3}$ and $2.7 \times 10^{-2} \mu \mathrm{g} \mathrm{m}^{-3}$, respectively, at $306-308 \mathrm{~K}$. Experimental partitioning coefficients of hexanedioic acid (M6) and pentanedioic acid (M4) were also consistent with theoretical calculations. The experimental partitioning coefficient of succinic acid (M2) was one or two orders of magnitude higher than theoretical calculations.

To conclude, using quantification of compounds in both gaseous and particulate phases, partitioning coefficients have been calculated. Differences can be observed in comparison with estimated and other experimental coefficients. Some hypotheses can be proposed to explain these discrepancies: (i) the estimated partitioning coefficient are calculated on the basis of estimations that may be wrong, which is one of the objectives of this study: providing partitioning coefficient obtained under real atmospheric conditions; (ii) reactions occurring in the particulate phase can disturb the equilibrium, leading to different partitioning coefficients than expected, which is another objective of our study: identifying unsuspected reaction pathways; and (iii) sampling positive artifacts upon particulate phase quantification as no denuder has been used for particulate phase sampling.

Artifacts seemed to be less important for di-acids than for carbonyl compounds. This was consistent with: (i) the Teflon-quartz nature of the filter media that is expected to reduce adsorption artifacts compared to quartz filters, even if this feature is not confirmed by Arp et al. (2007), and (ii) the artifact tendency expected to decrease compound volatility from carbonyl compounds to limonic acid (Volckens and Leith, 2003). 


\section{Conclusions and perspectives}

This work has provided a useful new analytical method, based on thermal desorption coupled with GC/MS, to explore the secondary organic matter composition at a molecular scale from a global point of view in both gas and particulate phases. Using separately but in parallel two derivatisation reagents, PFBHA and MTBSTFA, to analyse carbonyl compounds and organic acids and hydroxylated compounds, respectively, the method allows one to explore the chemical composition up to tri-functionalised species. Furthermore, it combines the classical advantages of thermal desorption - solvent-free, easy to use and fast - to analyse the same sample in both EI and CI modes, providing complementary structural information through the use of the re-collection option of commercial thermal desorbers. The potential of the method to determine the partitioning behaviour of a wide range of semi-volatile compounds has been demonstrated. Quantification in both gas and particulate phases is indeed validated for mono- and difunctionalised species and for hydroxyl di-acids. This is substantial progress compared to other techniques designed for compound partitioning studies. Compared to the TAG instrument (Isaacman et al., 2011), whose main advantage is based on on-line measurements, the developed method widens the range of detectable species to polar and multi-functionalised compounds. Compared to denuder/filter techniques (e.g. Leungsakul et al., 2005a; Temime et al., 2007), it provides a simpler way to study the partitioning of the secondary organic matter, avoiding time-consuming sample work-up procedures that are prone to sample losses during solvent extraction steps, with similar detection limits. It is an easy way to systematically assess, in simulation chamber experiments and in the field, the partitioning behaviour of semivolatile compounds, providing a set of data in a wide range of environmental conditions that allow support of a relevant integration of partitioning in models.

Application of the method to the study of limonene ozonolysis demonstrates the potential of the method to explore the chemical composition of a complex mixture in both gas and particulate phases, detecting both compounds already known as limonene oxidation products as well as a range of products detected for the first time. In the present study, 25 limonene oxidation products were positively or tentatively identified, 9 being in both gaseous and particulate phases and 12, among them tricarboxylic acids, hydroxyl dicarboxylic acids and oxodicarboxylic acids, being detected for the first time.

Quantification and partitioning coefficient estimations were provided, although as no precautions were taken to avoid or correct artifacts for the quantification of compounds in both gas and particulate phases compounds quantification, their relevance for atmospheric conclusions are limited here. Nevertheless, for decoupling gas and particulate sampling, the method allows testing a wide range of possibili- ties to limit (e.g. denuder use) or correct (e.g. backup filter use) artifacts.

Furthermore, derivatisation protocols should be improved to extend the range of quantifiable species to trifunctionalised compounds. To improve the confidence in the experimental determination of partitioning coefficients for tricarbonyl compounds, observed in limonene ozonolysis particulate-phase samples, it appears necessary to assess detection limits in the gas phase and to provide more relevant calibration curves for the particulate phase. It is demonstrated that ketodiacids and triacids are quantifiable in the gas phase and can be detected in limonene ozonolysis particulate phase samples. An adjustment of the derivatisation protocol for the particulate phase, such as a small increase of the derivatisation temperature, could provide relevant calibration curves.

In conclusion, the developed method allows to explore the chemical composition of the semi-volatile fraction of the oxygenated secondary organic matter and to assess its partitioning behaviour from mono to difunctionalised carbonyl, hydroxyl and organic acids species. Further improvement could enlarge the quantifiable species in both gas and particulate phases to trifunctionalised compounds. The method is applicable to both simulation chamber experiments under realistic humidity conditions and field campaigns.

\section{Supplementary material related to this article is available online at: http://www.atmos-meas-tech.net/5/ 1459/2012/amt-5-1459-2012-supplement.pdf.}

Acknowledgements. The authors wish to thank the EuPhoRe group at CEAM, Valencia for their contribution to simulation chamber experiments. This work was supported by the EC within the I3 project "Integrating of European Simulation Chambers for Investigating Atmospheric Processes - II" (EUROCHAMP-2, contract no. 228335).

Edited by: M. Sipilä

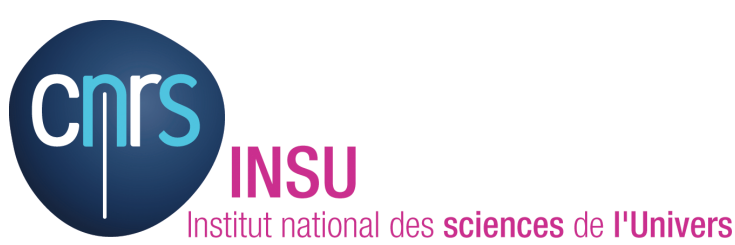

The publication of this article is financed by CNRS-INSU. 


\section{References}

Arp, H. P. H. and Goss, K. U.: Ambient Gas/Particle Partitioning. 3. Estimating Partition Coefficients of Apolar, Polar, and Ionizable Organic Compounds by Their Molecular Structure, Environ. Sci. Technol., 43, 1923-1929 doi:10.1021/es8025165, 2009.

Arp, H. P. H., Schwarzenbach, R. P., and Goss, K. U.: Equilibrium sorption of gaseous organic chemicals to fiber filters used for aerosol studies, Atmos. Environ., 41, 8241-8252, doi:10.1016/j.atmosenv.2007.06.026, 2007.

Asher, W. E. and Pankow, J. F.: Vapor pressure prediction for alkenoic and aromatic organic compounds by a UNIFAC-based group contribution method, Atmos. Environ., 40, 3588-3600, doi:10.1016/j.atmosenv.2005.12.004, 2006.

Baltussen, E. B., Cramers, C. C., and Sandra, P. S.: Sorptive sample preparation - a review, Anal. Bioanal. Chem., 373, 3-22, 2002.

Barley, M. H. and McFiggans, G.: The critical assessment of vapour pressure estimation methods for use in modelling the formation of atmospheric organic aerosol, Atmos. Chem. Phys., 10, 749767, doi:10.5194/acp-10-749-2010, 2010.

Beiner, K., Plewka, A., Haferkorn, S., Iinuma, Y., Engewald, W., and Herrmann, H.: Quantification of organic acids in particulate matter by coupling of thermally assisted hydrolysis and methylation with thermodesorption-gas chromatographymass spectrometry, J. Chromatogr. A, 1216, 6642-6650, doi:10.1016/j.chroma.2009.07.054, 2009.

Bessagnet, B., Menut, L., Curci, G., Hodzic, A., Guillaume, B., Liousse, C., Moukhtar, S., Pun, B., Seigneur, C., and Schulz, M.: Regional modeling of carbonaceous aerosols over Europe-focus on secondary organic aerosols, J. Atmos. Chem., 61, 175-202, doi:10.1007/s10874-009-9129-2, 2008.

Blake, R. S., Whyte, C., Hughes, C. O., Ellis, A. M., and Monks, P. S.: Demonstration of proton-transfer reaction time-of-flight mass spectrometry for real-time analysis of trace volatile organic compounds, Anal. Chem., 76, 3841-3845, doi:10.1021/ac0498260, 2004.

Camredon, M., Aumont, B., Lee-Taylor, J., and Madronich, S.: The SOA/VOC/NOx system: an explicit model of secondary organic aerosol formation, Atmos. Chem. Phys., 7, 5599-5610, doi:10.5194/acp-7-5599-2007, 2007.

Camredon, M., Hamilton, J. F., Alam, M. S., Wyche, K. P., Carr, T., White, I. R., Monks, P. S., Rickard, A. R., and Bloss, W. J.: Distribution of gaseous and particulate organic composition during dark $\alpha$-pinene ozonolysis, Atmos. Chem. Phys., 10, 2893-2917, doi:10.5194/acp-10-2893-2010, 2010.

Canagaratna, M. R., Jayne, J. T., Jimenez, J. L., Allan, J. D., Alfarra, M. R., Zhang, Q., Onasch, T. B., Drewnick, F., Coe, H., Middlebrook, A., Delia, A., Williams, L. R., Trimborn, A. M., Northway, M. J., DeCarlo, P. F., Kolb, C. E., Davidovits, P., and Worsnop, D. R.: Chemical and microphysical characterization of ambient aerosols with the aerodyne aerosol mass spectrometer, Mass Spectrom. Rev., 26, 185-222, 2007.

Cancilla, D. A. and Que Hee, S. S.: O-(2,3,4,5,6Pentafluorophenyl)methylhydroxylamine hydrochloride: a versatile reagent for the determination of carbonyl-containing compounds, J. Chromatogr. A, 627, 1-16, doi:10.1016/00219673(92)87181-7, 1992.

Cappa, C. D. and Jimenez, J. L.: Quantitative estimates of the volatility of ambient organic aerosol, Atmos. Chem. Phys., 10, 5409-5424, doi:10.5194/acp-10-5409-2010, 2010.
Carrasco, N., Doussin, J. F., O'Connor, M., Wenger, J. C., Picquet-Varrault, B., Durand-Jolibois, R., and Carlier, P.: Simulation chamber studies of the atmospheric oxidation of 2methyl-3-buten-2-ol: Reaction with hydroxyl radicals and ozone under a variety of conditions, J.Atmos. Chem., 56, 33-55, doi:10.1007/s10874-006-9041-y, 2007.

Castells, P., Santos, F. J., and Galceran, M. T.: Development of a sequential supercritical fluid extraction method for the analysis of nitrated and oxygenated derivatives of polycyclic aromatic hydrocarbons in urban aerosols, J. Chromatogr. A, 1010, 141-151, doi:10.1016/S0021-9673(03)01121-X, 2003.

Chan, M. N., Chan, A. W. H., Chhabra, P. S., Surratt, J. D., and Seinfeld, J. H.: Modeling of secondary organic aerosol yields from laboratory chamber data, Atmos. Chem. Phys., 9, 5669-5680, doi:10.5194/acp-9-5669-2009, 2009.

Chan, M. N., Surratt, J. D., Claeys, M., Edgerton, E. S., Tanner, R. L., Shaw, S. L., Zheng, M., Knipping, E. M., Eddingsaas, N. C., Wennberg, P. O., and Seinfeld, J. H.: Characterization and quantification of isoprene-derived epoxydiols in ambient aerosol in the Southeastern United States, Environ. Sci. Technol., 44, 45904596, doi:10.1021/es100596b, 2010.

Chi, Y., Feng, Y., Wen, S., Lü, H., Yu, Z., Zhang, W., Sheng, G., and Fu, J.: Determination of carbonyl compounds in the atmosphere by DNPH derivatisation and LC-ESI-MS/MS detection, Talanta, 72, 539-545, 2007.

Chiappini, L., Perraudin, E., Durand-Jolibois, R., and Doussin, J. F.: Development of a supercritical fluid extraction-gas chromatography-mass spectrometry method for the identification of highly polar compounds in secondary organic aerosols formed from biogenic hydrocarbons in smog chamber experiments, Anal. Bioanal. Chem., 386, 1749-1759, doi:10.1007/s00216006-0744-3, 2006.

Claeys, M., Graham, B., Vas, G., Wang, W., Vermeylen, R., Pashynska, V., Cafmeyer, J., Guyon, P., Andreae, M. O., Artaxo, P., and Maenhaut, W.: Formation of secondary organic aerosols through photooxidation of isoprene, Science, 303, 1173-1176, doi:10.1126/science.1092805, 2004.

Claeys, M., Szmigielski, R., Kourtchev, I., Van der Veken, P., Vermeylen, R., Maenhaut, W., Jaoui, M., Kleindienst, T. E., Lewandowski, M., Offenberg, J. H., and Edney, E. O.: Hydroxydicarboxylic acids: markers for secondary organic aerosol from the photooxidation of $\alpha$-pinene, Environ. Sci. Technol., 41, 1628-1634, doi:10.1021/es0620181, 2007.

Claeys, M., Iinuma, Y., Szmigielski, R., Surratt, J. D., Blockhuys, F., Van Alsenoy, C., Boge, O., Sierau, B., Gomez-Gonzalez, Y., Vermeylen, R., Van der Veken, P., Shahgholi, M., Chan, A. W. H., Herrmann, H., Seinfeld, J. H., and Maenhaut, W.: Terpenylic acid and related compounds from the oxidation of a-pinene: implications for new particle formation and growth above forests, Environ. Sci. Technol., 43, 6976-6982, doi:10.1021/es9007596, 2009.

Clausen, P. A., Wilkins, C. K., Wolkoff, P., and Nielsen, G. D.: Chemical and biological evaluation of a reaction mixture of R(+)-limonene/ozone: Formation of strong airway irritants, Environ. Int., 26, 511-522, doi:10.1016/S0160-4120(01)00035-6, 2001.

Coleman, B. K., Lunden, M. M., Destaillats, H., and Nazaroff, W. W.: Secondary organic aerosol from ozone-initiated reactions with terpene-rich household products, Atmos. Environ., 42, 
8234-8245, doi:10.1016/j.atmosenv.2008.07.031, 2008.

de Gouw, J. and Warneke, C.: Measurements of volatile organic compounds in the earth's atmosphere using proton-transferreaction mass spectrometry, Mass Spectrom. Rev., 26, 223-257, 2007.

Docherty, K. S. and Ziemann, P. J.: Effects of stabilized Criegee intermediate and $\mathrm{OH}$ radical scavengers on aerosol formation from reactions of $\alpha$-pinene with $\mathrm{O}_{3}$, Aerosol Sci. Tech., 37, 877-891, doi:10.1080/02786820300930, 2003.

Donahue, N. M., Robinson, A. L., Stanier, C. O., and Pandis, S. N.: Coupled partitioning, dilution, and chemical aging of semivolatile organics, Environ. Sci. Technol., 40, 02635-02643, doi:10.1021/es052297c, 2006.

Donahue, N. M., Robinson, A. L., and Pandis, S. N.: Atmospheric organic particulate matter: From smoke to secondary organic aerosol, Atmos. Environ., 43, 94-106, doi:10.1016/j.atmosenv.2008.09.055, 2009.

Edney, E. O., Kleindienst, T. E., Jaoui, M., Lewandowski, M., Offenberg, J. H., Wang, W., and Claeys, M.: Formation of 2methyl tetrols and 2-methylglyceric acid in secondary organic aerosol from laboratory irradiated isoprene/NOX/SO2/air mixtures and their detection in ambient PM2.5 samples collected in the eastern United States, Atmos. Environ., 39, 5281-5289, doi:10.1016/j.atmosenv.2005.05.031, 2005.

Farina, S. C., Adams, P. J., and Pandis, S. N.: Modeling global secondary organic aerosol formation and processing with the volatility basis set: Implications for anthropogenic secondary organic aerosol, J. Geophys. Res.-Atmos., 115, 17, doi:10.1029/2009jd013046, 2010.

Forester, C. D. and Wells, J. R.: Yields of carbonyl products from gas-phase reactions of fragrance compounds with $\mathrm{OH}$ radical and ozone, Environ. Sci. Technol., 43, 3561-3568, doi:10.1021/es803465v, 2009.

Forstner, H. J. L., Flagan, R. C., and Seinfeld, J. H.: Molecular speciation of secondary organic aerosol from photooxidation of the higher alkenes: 1-octene and 1-decene, Atmos. Environ., 31, 1953-1964, doi:10.1016/s1352-2310(96)00356-1, 1997.

Goldstein, A. H., Worton, D. R., Williams, B. J., Hering, S. V., Kreisberg, N. M., Panic, O., and Górecki, T.: Thermal desorption comprehensive two-dimensional gas chromatography for insitu measurements of organic aerosols, J. Chromatogr. A, 1186, 340-347, doi:10.1016/j.chroma.2007.09.094, 2008.

Gómez-González, Y., Surratt, J. D., Cuyckens, F., Szmigielski, R.,Vermeylen, R., Jaoui, M., Lewandowski, M., Offenberg, J. H., Kleindienst, T. E., Edney, E. O., Blockhuys, F., Van Alsenoy, C., Maenhaut, W., and Claeys, M.: Characterisation of organosulfates from the photooxidation of isoprene and unsaturated fatty acids in ambient aerosol using liquid chromatography/(-) electrospray ionization mass spectrometry, J. Mass Spectrom., 43, 371-382, 2008.

Gonzalez-Flesca, N. and Frezier, A.: A new laboratory test chamber for the determination of diffusive sampler uptake rates, Atmos. Environ., 39, 4049-4056, doi:10.1016/j.atmosenv.2005.03.025, 2005.

Graber, E. R. and Rudich, Y.: Atmospheric HULIS: How humic-like are they? A comprehensive and critical review, Atmos. Chem. Phys., 6, 729-753, doi:10.5194/acp-6-729-2006, 2006.

Grieshop, A. P., Miracolo, M. A., Donahue, N. M., and Robinson, A. L.: Constraining the volatility distribution and gas-particle partitioning of combustion aerosols using isothermal dilution and thermodenuder measurements, Environ. Sci. Technol., 43, 4750 4756, doi:10.1021/es8032378, 2009.

Griffin, R. J., Cocker, D. R., III, Seinfeld, J. H., and Dabdub, D.: Estimate of global atmospheric organic aerosol from oxidation of biogenic hydrocarbons, Geophys. Res. Lett., 26, 2721-2724, doi:10.1029/1999GL900476, 1999.

Guenther, A., Hewitt, C. N., Erickson, D., Fall, R., Geron, C., Graedel, T., Harley, P., Klinger, L., Lerdau, M., McKay, W. A., Pierce, T., Scholes, B., Steinbrecher, R., Tallamraju, R., Taylor, J., and Zimmerman, P.: A global-model of natural volatile organic-compound emissions, J. Geophys. Res.-Atmos., 100, 8873-8892, doi:10.1029/94jd02950, 1995.

Hallquist, M., Wenger, J. C., Baltensperger, U., Rudich, Y., Simpson, D., Claeys, M., Dommen, J., Donahue, N. M., George, C., Goldstein, A. H., Hamilton, J. F., Herrmann, H., Hoffmann, T., Iinuma, Y., Jang, M., Jenkin, M. E., Jimenez, J. L., Kiendler-Scharr, A., Maenhaut, W., McFiggans, G., Mentel, Th. F., Monod, A., Prévôt, A. S. H., Seinfeld, J. H., Surratt, J. D., Szmigielski, R., and Wildt, J.: The formation, properties and impact of secondary organic aerosol: current and emerging issues, Atmos. Chem. Phys., 9, 5155-5236, doi:10.5194/acp-9-51552009, 2009.

Hamilton, J. F., Webb, P. J., Lewis, A. C., and Reviejo, M. M.: Quantifying small molecules in secondary organic aerosol formed during the photo-oxidation of toluene with hydroxyl radicals, Atmos. Environ., 39, 7263-7275, doi:10.1016/j.atmosenv.2005.09.006, 2005.

Hamilton, J. F., Rami Alfarra, M., Wyche, K. P., Ward, M. W. Lewis, A. C., McFiggans, G. B., Good, N., Monks, P. S., Carr, T., White, I. R., and Purvis, R. M.: Investigating the use of secondary organic aerosol as seed particles in simulation chamber experiments, Atmos. Chem. Phys., 11, 5917-5929, doi:10.5194/acp11-5917-2011, 2011

Hansen, K. J., Nansen, B. N., Cravens, E., and Sievers, R. E.: Supercritical-fluid extraction gas-chromatographic analysis of organic-compounds in atmospheric aerosols, Anal. Chem., 67, 3541-3549, doi:10.1021/ac00115a025, 1995.

Hays, M. D. and Lavrich, R. J.: Developments in direct thermal extraction gas chromatography-mass spectrometry of fine aerosols, TrAC Trend Anal. Chem., 26, 88-102, 2007.

Healy, R. M., Wenger, J. C., Metzger, A., Duplissy, J., Kalberer, M., and Dommen, J.: Gas/particle partitioning of carbonyls in the photooxidation of isoprene and 1,3,5-trimethylbenzene, Atmos. Chem. Phys., 8, 3215-3230, doi:10.5194/acp-8-3215-2008, 2008.

Healy, R. M., Temime, B., Kuprovskyte, K., and Wenger, J. C.: Effect of relative humidity on gas/particle partitioning and aerosol mass yield in the photooxidation of p-xylene, Environ. Sci. Technol., 43, 1884-1889, doi:10.1021/es802404z, 2009.

Ho, S. S. H. and Yu, J. Z.: Feasibility of collection and analysis of airborne carbonyls by on-sorbent derivatization and thermal desorption, Anal. Chem., 74, 1232-1240, doi:10.1021/ac015708q, 2002.

Ho, S. S. H. and Yu, J. Z.: Determination of airborne carbonyls: Comparison of a thermal desorption/GC method with the standard DNPH/HPLC method, Environ. Sci. Technol., 38, 862-870, doi:10.1021/es034795w, 2004. 
IPCC: Fourth Assessment Report: Climate Change 2007, The Physical Science Basis, Cambridge University Press, Cambridge, United Kingdom and New York, NY, USA., 2007.

Isaacman, G., Worton, D. R., Kreisberg, N. M., Hennigan, C. J., Teng, A. P., Hering, S. V., Robinson, A. L., Donahue, N. M., and Goldstein, A. H.: Understanding evolution of product composition and volatility distribution through in-situ $\mathrm{GC} \times \mathrm{GC}$ analysis: a case study of longifolene ozonolysis, Atmos. Chem. Phys., 11, 5335-5346, doi:10.5194/acp-11-5335-2011, 2011.

Jakober, C. A., Robert, M. A., Riddle, S. G., Destaillats, H., Charles, M. J., Green, P. G., and Kleeman, M. J.: Carbonyl emissions from gasoline and diesel motor vehicles, Environ. Sci. Technol., 42, 4697-4703, doi:10.1021/es7029174, 2008.

Jaoui, M. and Kamens, R. M.: Gaseous and particulate oxidation products analysis of a mixture of $\alpha$-pinene $+\beta$-pinene/O3/Air in the absence of light and $\alpha$-pinene $+\beta$-pinene/NOx/Air in the presence of natural sunlight, J. Atmos. Chem., 44, 259-297, 2003

Jaoui, M., Leungsakul, S., and Kamens, R. M.: Gas and particle products distribution from the reaction of $\beta$-caryophyllene with ozone, J. Atmos. Chem., 45, 261-287, 2003.

Jaoui, M., Corse, E., Kleindienst, T. E., Offenberg, J. H., Lewandowski, M., and Edney, E. O.: Analysis of secondary organic aerosol compounds from the photooxidation of d-limonene in the presence of $\mathrm{NO}_{\mathrm{x}}$ and their detection in ambient $\mathrm{PM}_{2.5}$, Environ. Sci. Technol., 40, 3819-3828, doi:10.1021/es052566z, 2006.

Jardine, K., Serrano, A. Y., Arneth, A., Abrell, L., Jardine, A., van Haren, J., Artaxo, P., Rizzo, L. V., Ishida, F. Y., Karl, T., Kesselmeier, J., Saleska, S., and Huxman, T.: Within-canopy sesquiterpene ozonolysis in Amazonia, J. Geophys. Res.-Atmos., 116, 10, doi:10.1029/2011jd016243, 2011.

Jenkin, M. E.: Modelling the formation and composition of secondary organic aerosol from $\alpha$ - and $\beta$-pinene ozonolysis using MCM v3, Atmos. Chem. Phys., 4, 1741-1757, doi:10.5194/acp4-1741-2004, 2004.

Jenkin, M. E., Saunders, S. M., and Pilling, M. J.: The tropospheric degradation of volatile organic compounds: a protocol for mechanism development, Atmos. Environ., 31, 81-104, doi:10.1016/S1352-2310(96)00105-7, 1997.

Jonsson, A. M., Hallquist, M., and Ljungstrom, E.: Influence of $\mathrm{OH}$ scavenger on the water effect on secondary organic aerosol formation from ozonolysis of limonene, delta(3)-carene, and alpha-pinene, Environ. Sci. Technol., 42, 5938-5944, doi:10.1021/es702508y, 2008.

Kalberer, M., Yu, J., Cocker, D. R., Flagan, R. C., and Seinfeld, J. H.: Aerosol formation in the cyclohexene-ozone system, Environ. Sci. Technol., 34, 4894-4901, doi:10.1021/es001180f, 2000.

Kanakidou, M., Seinfeld, J. H., Pandis, S. N., Barnes, I., Dentener, F. J., Facchini, M. C., Van Dingenen, R., Ervens, B., Nenes, A., Nielsen, C. J., Swietlicki, E., Putaud, J. P., Balkanski, Y., Fuzzi, S., Horth, J., Moortgat, G. K., Winterhalter, R., Myhre, C. E. L., Tsigaridis, K., Vignati, E., Stephanou, E. G., and Wilson, J.: Organic aerosol and global climate modelling: a review, Atmos. Chem. Phys., 5, 1053-1123, doi:10.5194/acp-5-1053-2005, 2005.

Kitanovski, Z., Grgic, I., and Veber, M.: Characterization of carboxylic acids in atmospheric aerosols using hydrophilic interaction liquid chromatography tandem mass spectrometry, J. Chromatogr. A, 1218, 4417-4425, doi:10.1016/j.chroma.2011.05.020, 2011.

Kleindienst, T. E., Conver, T. S., McIver, C. D., and Edney, E. O.: Determination of secondary organic aerosol products from the photooxidation of toluene and their implications in ambient PM2.5, J. Atmos. Chem., 47, 79-100, 2004.

Kroll, J. H., Ng, N. L., Murphy, S. M., Flagan, R. C., and Seinfeld, J. H.: Secondary organic aerosol formation from isoprene photooxidation, Environ. Sci. Technol., 40, 1869-1877, doi:10.1021/es0524301, 2006.

Kroll, J. H., Chan, A. W. H., Ng, N. L., Flagan, R. C., and Seinfeld, J. H.: Reactions of semivolatile organics and their effects on secondary organic aerosol formation, Environ. Sci. Technol., 41, 3545-3550, doi:10.1021/es062059x, 2007.

Langer, S., Moldanová, J., Arrhenius, K., Ljungström, E., and Ekberg, L.: Ultrafine particles produced by ozone/limonene reactions in indoor air under low/closed ventilation conditions, Atmos. Environ., 42, 4149-4159, doi:10.1016/j.atmosenv.2008.01.034, 2008.

Lazaridis, M.: Gas-particle partitioning of organic compounds in the atmosphere, J. Aerosol Sci., 30, 1165-1170, doi:10.1016/S0021-8502(98)00788-5, 1999.

Lee, B.-H., Pierce, J. R., Engelhart, G. J., and Pandis, S. N.: Volatility of secondary organic aerosol from the ozonolysis of monoterpenes, Atmos. Environ., 45, 2443-2452, doi:10.1016/j.atmosenv.2011.02.004, 2011.

Lee, S., Jang, M., and Kamens, R. M.: SOA formation from the photooxidation of a-pinene in the presence of freshly emitted diesel soot exhaust, Atmos. Environ., 38, 2597-2605, doi:10.1016/j.atmosenv.2003.12.041, 2004.

Legrand, M., Preunkert, S., Galy-Lacaux, C., Liousse, C., and Wagenbach, D.: Atmospheric year-round records of dicarboxylic acids and sulfate at three French sites located between 630 and $4360 \mathrm{~m}$ elevation, J. Geophys. Res.-Atmos., 110, 11, doi:10.1029/2004jd005515, 2005.

Leungsakul, S., Jaoui, M., and Kamens, R. M.: Kinetic mechanism for predicting secondary organic aerosol formation from the reaction of d-limonene with ozone, Environ. Sci. Technol., 39, 9583-9594, doi:10.1021/es0492687, 2005a.

Leungsakul, S., Jeffries, H. E., and Kamens, R. M.: A kinetic mechanism for predicting secondary aerosol formation from the reactions of d-limonene in the presence of oxides of nitrogen and natural sunlight, Atmos. Environ., 39, 7063-7082, doi:10.1016/j.atmosenv.2005.08.024, 2005b.

Li, J., Feng, Y. L., Xie, C. J., Huang, J., Yu, J. Z., Feng, J. L., Sheng, G. Y., Fu, J. M., and Wu, M. H.: Determination of gaseous carbonyl compounds by their pentafluorophenyl hydrazones with gas chromatography/mass spectrometry, Anal. Chim. Acta, 635, 84-93, doi:10.1016/j.aca.2008.12.041, 2009.

Li, Y.-c. and Yu, J. Z.: Simultaneous determination of mono- and dicarboxylic acids, $\omega$-oxo-carboxylic acids, midchain ketocarboxylic acids, and aldehydes in atmospheric aerosol samples, Environ. Sci. Technol., 39, 7616-7624, doi:10.1021/es050896d, 2005.

Liggio, J. and McLaren, R.: An optimized method for the determination of volatile and semi-volatile aldehydes and ketones in ambient particulate matter, Int. J. Environ. Anal. Chem., 83, 819835, doi:10.1080/03067310310001597653, 2003. 
Martin, N. A., Marlow, D. J., Henderson, M. H., Goody, B. A., and Quincey, P. G.: Studies using the sorbent Carbopack X for measuring environmental benzene with Perkinâ€"Elmer-type pumped and diffusive samplers, Atmos. Environ., 37, 871-879, doi:10.1016/S1352-2310(02)01000-2, 2003.

Matsunaga, S., Mochida, M., and Kawamura, K.: High abundance of gaseous and particulate 4-oxopentanal in the forestal atmosphere, Chemosphere, 55, 1143-1147, doi:10.1016/j.chemosphere.2003.10.004, 2004.

Monks, P. S., Granier, C., Fuzzi, S., Stohl, A., Williams, M. L., Akimoto, H., Amann, M., Baklanov, A., Baltensperger, U., Bey, I., Blake, N., Blake, R. S., Carslaw, K., Cooper, O. R., Dentener, F., Fowler, D., Fragkou, E., Frost, G. J., Generoso, S., Ginoux, P., Grewe, V., Guenther, A., Hansson, H. C., Henne, S., Hjorth, J., Hofzumahaus, A., Huntrieser, H., Isaksen, I. S. A., Jenkin, M. E., Kaiser, J., Kanakidou, M., Klimont, Z., Kulmala, M., Laj, P., Lawrence, M. G., Lee, J. D., Liousse, C., Maione, M., McFiggans, G., Metzger, A., Mieville, A., Moussiopoulos, N., Orlando, J. J., O’Dowd, C. D., Palmer, P. I., Parrish, D. D., Petzold, A., Platt, U., Pöschl, U., Prévôt, A. S. H., Reeves, C. E., Reimann, S., Rudich, Y., Sellegri, K., Steinbrecher, R., Simpson, D., ten Brink, H., Theloke, J., van der Werf, G. R., Vautard, R., Vestreng, V., Vlachokostas, C., and von Glasow, R.: Atmospheric composition change - global and regional air quality, Atmos. Environ., 43, 5268-5350, doi:10.1016/j.atmosenv.2009.08.021, 2009.

Müller, K., Haferkorn, S., Grabmer, W., Wisthaler, A., Hansel, A., Kreuzwieser, J., Cojocariu, C., Rennenberg, H., and Herrmann, H.: Biogenic carbonyl compounds within and above a coniferous forest in Germany, Atmos. Environ., 40, Supplement 1, 81-91, doi:10.1016/j.atmosenv.2005.10.070, 2006.

Myrdal, P. B. and Yalkowsky, S. H.: Estimating pure component vapor pressures of complex organic molecules, Ind. Eng. Chem. Res., 36, 2494-2499, doi:10.1021/ie9502421, 1997.

Nannoolal, Y., Rarey J., and Ramjugernath, D.: Estimation of pure component properties: Part 3. Estimation of the vapor pressure of non-electrolyte organic compounds via group contributions and group interactions, Fluid Phase Equilibr., 269, 117-133, doi:10.1016/j.fluid.2008.04.020, 2008.

Nolte, C. G., Schauer, J. J., Cass, G. R., and Simoneit, B. R. T.: Highly polar organic compounds present in wood smoke and in the ambient atmosphere, Environ. Sci. Technol., 35, 1912-1919, doi:10.1021/es001420r, 2001.

Northcross, A. L. and Jang, M.: Heterogeneous SOA yield from ozonolysis of monoterpenes in the presence of inorganic acid, Atmos. Environ., 41, 1483-1493, doi:10.1016/j.atmosenv.2006.10.009, 2007.

Odum, J. R., Hoffmann, T., Bowman, F., Collins, D., Flagan, R. C., and Seinfeld, J. H.: Gas/particle partitioning and secondary organic aerosol yields, Environ. Sci. Technol., 30, 2580-2585, 1996.

Orasche, J., Schnelle-Kreis, J., Abbaszade, G., and Zimmermann, R.: Technical Note: In-situ derivatization thermal desorption GC-TOFMS for direct analysis of particle-bound non-polar and polar organic species, Atmos. Chem. Phys., 11, 8977-8993, doi:10.5194/acp-11-8977-2011, 2011.

Ortiz, R., Enya, K., Sekiguchi, K., and Sakamoto, K.: Experimental testing of an annular denuder and filter system to measure gas-particle partitioning of semivolatile bifunctional carbonyls in the atmosphere, Atmos. Environ., 43, 382-388, doi:10.1016/j.atmosenv.2008.09.074, 2009.

Ortiz, R., Enya, K., and Sakamoto, K.: Experimental Determination of the Partition Coefficient for Bifunctional Carbonyls in the Atmosphere and in Smog Chamber, in: NATO Science for Peace and Security Series B-Physics and Biophysics, edited by: NatoChal. M., 265-269, 2010.

Pacolay, B. D., Ham, J. E., Slaven, J. E., and Wells, J. R.: Feasibility of detection and quantification of gas-phase carbonyls in indoor environments using PFBHA derivatization and solidphase microextraction (SPME), J. Environ. Monit., 10, 853-860, doi:10.1039/b801926f, 2008.

Pankow, J. F.: An absorption model of gas/particle partitioning of organic compounds in the atmosphere, Atmos. Environ., 28, 185-188, doi:10.1016/1352-2310(94)90093-0, 1994.

Pankow, J. F.: On the ability of the gas/particle partitioning constant $\mathrm{Kp}$ to consider the effects of mean MW and the presence of high MW compounds, Atmos. Environ., 45, 1213-1216, doi:10.1016/j.atmosenv.2010.11.041, 2011.

Pankow, J. F. and Asher, W. E.: SIMPOL.1: a simple group contribution method for predicting vapor pressures and enthalpies of vaporization of multifunctional organic compounds, Atmos. Chem. Phys., 8, 2773-2796, doi:10.5194/acp-8-27732008, 2008.

Parikh, H. M., Carlton, A. G., Vizuete, W., and Kamens, R. M.: Modeling secondary organic aerosol using a dynamic partitioning approach incorporating particle aqueous-phase chemistry, Atmos. Environ., 45, 1126-1137, doi:10.1016/j.atmosenv.2010.11.027, 2011.

Pietrogrande, M. C. and Bacco, D.: GC-MS analysis of watersoluble organics in atmospheric aerosol: Response surface methodology for optimizing silyl-derivatization for simultaneous analysis of carboxylic acids and sugars, Anal. Chim. Acta, 689 257-264, doi:10.1016/j.aca.2011.01.047, 2011.

Pietrogrande, M. C., Bacco, D., and Mercuriali, M.: GC-MS analysis of low-molecular-weight dicarboxylic acids in atmospheric aerosol: comparison between silylation and esterification derivatization procedures, Anal. Bioanal. Chem., 396, 877-885, 2010.

Pol, J., Hohnova, B., Jussila, M., and Hyotylainen, T.: Comprehensive two-dimensional liquid chromatography-time-offlight mass spectrometry in the analysis of acidic compounds in atmospheric aerosols, J. Chromatogr. A, 1130, 64-71, doi:10.1016/j.chroma.2006.04.050, 2006.

Prather, K. A., Hatch, C. D., and Grassian, V. H.: Analysis of Atmospheric Aerosols, in: Annu. Rev. Anal. Chem., Annual Reviews, Palo Alto, 485-514, 2008.

Rudich, Y.: Laboratory Perspectives on the Chemical Transformations of Organic Matter in Atmospheric Particles, Chem. Rev. 103, 5097-5124, doi:10.1021/cr020508f, 2003.

Rudich, Y., Donahue, N. M., and Mentel, T. F.: Aging of organic aerosol: Bridging the gap between laboratory and field studies, Annu. Rev. Phys. Chem., 58, 321-352, doi:10.1146/annurev.physchem.58.032806.104432, 2007.

Saathoff, H., Naumann, K.-H., Möhler, O., Jonsson, Å. M., Hallquist, M., Kiendler-Scharr, A., Mentel, Th. F., Tillmann, R., and Schurath, U.: Temperature dependence of yields of secondary organic aerosols from the ozonolysis of $\alpha$-pinene and limonene, Atmos. Chem. Phys., 9, 1551-1577, doi:10.5194/acp-9-15512009, 2009. 
Sarwar, G. and Corsi, R.: The effects of ozone/limonene reactions on indoor secondary organic aerosols, Atmos. Environ., 41, 959973, doi:10.1016/j.atmosenv.2006.09.032, 2007.

Sato, K., Takami, A., Isozaki, T., Hikida, T., Shimono, A., and Imamura, T.: Mass spectrometric study of secondary organic aerosol formed from the photo-oxidation of aromatic hydrocarbons, Atmos. Environ., 44, 1080-1087, doi:10.1016/j.atmosenv.2009.12.013, 2010.

Saunders, S. M., Jenkin, M. E., Derwent, R. G., and Pilling, M. J.: Protocol for the development of the Master Chemical Mechanism, MCM v3 (Part A): tropospheric degradation of nonaromatic volatile organic compounds, Atmos. Chem. Phys., 3, 161-180, doi:10.5194/acp-3-161-2003, 2003.

Seinfeld, J. H. and Pankow, J. F.: Organic atmospheric particulate material, Annu. Rev. Phys. Chem., 54, 121-140, doi:10.1146/annurev.physchem.54.011002.103756, 2003.

Sheesley, R. J., DeMinter, J. T., Meiritz, M., Snyder, D. C., and Schauer, J. J.: Temporal trends in motor vehicle and secondary organic tracers using in situ methylation thermal desorption GC-MS, Environ. Sci. Technol., 44, 9398-9404, doi:10.1021/es102301t, 2010.

Shimmo, M., Jäntti, J., Aalto, P., Hartonen, K., Hyötyläinen, T., Kulmala, M., and Riekkola, M.-L.: Characterisation of organic compounds in aerosol particles from a Finnish forest by on-line coupled supercritical fluid extraction-liquid chromatography-gas chromatography-mass spectrometry, Anal. Bioanal. Chem., 378, 1982-1990, 2004.

Singer, B. C., Destaillats, H., Hodgson, A. T., and Nazaroff, W. W.: Cleaning products and air fresheners: emissions and resulting concentrations of glycol ethers and terpenoids, Indoor Air, 16, 179-191, 2006.

Sinha, V., Williams, J., Lelieveld, J., Ruuskanen, T. M., Kajos, M. K., Patokoski, J., Hellen, H., Hakola, H., Mogensen, D., Boy, M., Rinne, J., and Kulmala, M.: OH reactivity measurements within a boreal forest: evidence for unknown reactive emissions, Environ. Sci. Technol., 44, 6614-6620, doi:10.1021/es101780b, 2010.

Sullivan, R. C. and Prather, K. A.: Recent advances in our understanding of atmospheric chemistry and climate made possible by on-line aerosol analysis instrumentation, Anal. Chem., 77, 38613886, doi:10.1021/ac050716i, 2005.

Sun, J. and Ariya, P. A.: Atmospheric organic and bio-aerosols as cloud condensation nuclei $(\mathrm{CCN})$ : A review, Atmos. Environ., 40, 795-820, doi:10.1016/j.atmosenv.2005.05.052, 2006.

Sun, T., Wang, Y., Zhang, C., Sun, X., and Wang, W.: The chemical mechanism of the limonene ozonolysis reaction in the SOA formation: A quantum chemistry and direct dynamic study, Atmos. Environ., 45, 1725-1731, doi:10.1016/j.atmosenv.2010.12.054, 2011.

Szmigielski, R., Surratt, J. D., Vermeylen, R., Szmigielska, K., Kroll, J. H., Ng, N. L., Murphy, S. M., Sorooshian, A., Seinfeld, J. H., and Claeys, M.: Characterization of 2-methylglyceric acid oligomers in secondary organic aerosol formed from the photooxidation of isoprene using trimethylsilylation and gas chromatography/ion trap mass spectrometry, J. Mass Spectrom., 42, 101-116, 2007.

Temime, B., Healy, R. M., and Wenger, J. C.: A denuder-filter sampling technique for the detection of gas and particle phase carhonyl compounds, Environ. Sci. Technol., 41, 6514-6520, doi:10.1021/es070802v, 2007.
Tsimpidi, A. P., Karydis, V. A., Zavala, M., Lei, W., Molina, L., Ulbrich, I. M., Jimenez, J. L., and Pandis, S. N.: Evaluation of the volatility basis-set approach for the simulation of organic aerosol formation in the Mexico City metropolitan area, Atmos. Chem. Phys., 10, 525-546, doi:10.5194/acp-10-525-2010, 2010.

Valorso, R., Aumont, B., Camredon, M., Raventos-Duran, T., Mouchel-Vallon, C., Ng, N. L., Seinfeld, J. H., Lee-Taylor, J., and Madronich, S.: Explicit modelling of SOA formation from $\alpha$-pinene photooxidation: sensitivity to vapour pressure estimation, Atmos. Chem. Phys., 11, 6895-6910, doi:10.5194/acp-116895-2011, 2011.

Vivanco, M. G., Santiago, M., Martinez-Tarifa, A., Borras, E., Rodenas, M., Garcia-Diego, C., and Sanchez, M.: SOA formation in a photoreactor from a mixture of organic gases and HONO for different experimental conditions, Atmos. Environ., 45, 708715, doi:10.1016/j.atmosenv.2010.09.059, 2011.

Volckens, J. and Leith, D.: Effects of sampling bias on gas-particle partitioning of semi-volatile compounds, Atmos. Environ., 37, 3385-3393, doi:10.1016/S1352-2310(03)00356-X, 2003.

Volkamer, R., Martini, F. S., Molina, L. T., Salcedo, D., Jimenez, J. L., and Molina, M. J.: A missing sink for gas-phase glyoxal in Mexico City: Formation of secondary organic aerosol, Geophys. Res. Lett., 34, 5, doi:10.1029/2007gl030752, 2007.

Walser, M. L., Park, J., Gomez, A. L., Russell, A. R., and Nizkorodov, S. A.: Photochemical aging of secondary organic aerosol particles generated from the oxidation of d-limonene, J. Phys. Chem. A, 111, 1907-1913, doi:10.1021/jp0662931, 2007.

Wan, E. C. H. and Yu, J. Z.: Analysis of sugars and sugar polyols in atmospheric aerosols by chloride attachment in liquid chromatography/negative ion electrospray mass spectrometry, Environ. Sci. Technol., 41, 2459-2466, doi:10.1021/es062390g, 2007.

Wang, J., Doussin, J. F., Perrier, S., Perraudin, E., Katrib, Y., Pangui, E., and Picquet-Varrault, B.: Design of a new multi-phase experimental simulation chamber for atmospheric photosmog, aerosol and cloud chemistry research, Atmos. Meas. Tech., 4, 2465-2494, doi:10.5194/amt-4-2465-2011, 2011.

Wedel, A., Müller, K.-P., Ratte, M., and Rudolph, J.: Measurements of Volatile Organic Compounds (VOC) during POPCORN 1994: Applying a new on-line GC-MS technique, J. Atmos. Chem., 31, 73-103, 1998.

Williams, B. J., Goldstein, A. H., Kreisberg, N. M., and Hering, S. V.: An In-Situ Instrument for Speciated Organic Composition of Atmospheric Aerosols: Thermal Desorption Aerosol GC/MS-FID (TAG), Aerosol Sci. Tech., 40, 627-638, doi:10.1080/02786820600754631, 2006.

Woo, K.-L. and Kim, J.-I.: New hydrolysis method for extremely small amount of lipids and capillary gas chromatographic analysis as $\mathrm{N}(\mathrm{O})$-tert.-butyldimethylsilyl fatty acid derivatives compared with methyl ester derivatives, J. Chromatogr. A, 862, 199208, doi:10.1016/S0021-9673(99)00934-6, 1999.

Wu, L. J. and Hee, S. S. Q.: A solid sorbent personal air sampling method for aldehydes, Am. Ind. Hyg. Assoc. J., 56, 362-367, doi:10.1080/15428119591016980, 1995.

Wu, T., Wang, X., Li, D., Sheng, G., and Fu, J.: Determination of trace volatile fatty acids in ambient air by capillary gas chromatography-mass spectrometry in SIM mode, Int. J. Environ. Anal. Chem., 88, 1107-1115, doi:10.1080/03067310802447034, 2008. 
Xu, X., Stee, L. L. P., Williams, J, Beens, J., Adahchour, M., Vreuls, R. J. J., Brinkman, U. A., and Lelieveld, J.: Comprehensive twodimensional gas chromatography $(\mathrm{GC} \times \mathrm{GC})$ measurements of volatile organic compounds in the atmosphere, Atmos. Chem. Phys., 3, 665-682, doi:10.5194/acp-3-665-2003, 2003.

Yasmeen, F., Szmigielski, R., Vermeylen, R., Gómez-González, Y., Surratt, J. D., Chan, A. W. H., Seinfeld, J. H., Maenhaut, W., and Claeys, M.: Mass spectrometric characterization of isomeric terpenoic acids from the oxidation of $\alpha$-pinene, $\beta$-pinene, $\mathrm{d}$ limonene, and $\Delta 3$-carene in fine forest aerosol, J. Mass Spectrom., 46, 425-442, 2011.
Yu, J., Cocker, D. R., Griffin, R. J., Flagan, R. C., and Seinfeld, J. H.: Gas-phase ozone oxidation of monoterpenes: gaseous and particulate products, J. Atmos. Chem., 34, 207-258, 1999.

Zhang, Q., Jimenez, J. L., Canagaratna, M. R., Ulbrich, I. M., Ng, N. L., Worsnop, D. R., and Sun, Y.: Understanding atmospheric organic aerosols via factor analysis of aerosol mass spectrometry: a review, Anal. Bioanal. Chem., 401, 3045-3067, 2011. 